\title{
Reformas institucionales para mejorar la gobernanza democrática en la Unión Europea
}

\author{
Institutional Reforms to Improve \\ Democratic Governance in the European Union \\ Juan José Álvarez Rubio \\ Catedrático Derecho Internacional Privado, UPV/EHU; \\ Secretario General de Globernance. \\ juanjose.alvarez@ehu.es
}

Sumario: I. Consideraciones introductorias.-II. Europa: entre lo intergubernamental y lo supraestatal.-III. Una nueva gobernanza para Europa.-IV. Conclusiones.-V. Bibliografía

Resumen: Ante el desconcierto institucional que caracteriza a la Unión Europea es preciso hacer balance y reflexionar sobre los aspectos positivos que el avance de la construcción europea ha supuesto para los todavía veintiocho Estados integrados en esta compleja entidad supranacional, y cuyo andamiaje debe ser necesariamente renovado para garantizar el dinamismo y la agilidad en la toma de decisiones que requiere el contexto de un mundo globalizado. La UE debe ser capaz de responder a los retos que tal globalización mundial implica, ad intra y ad extra.

Palabras clave: Construcción europea; crisis institucional; avances y retos; balance y costes de la No Europa.

Abstract: Given the institutional confusion that characterizes the European Union it is necessary to take stock and reflect on the positive aspects that the advance of European construction has meant for the 28 States that make up this complex supranational entity, and whose scaffolding must necessarily be renewed to guarantee the dynamism and agility in the decision-making required by the context of a world globalized and in which the EU must be able to respond to the challenges that such global globalization implies, ad intra and ad extra.

Keywords: European construction; institutional crisis; advances and challenges; balance and costs of the Non-Europe. 


\section{Consideraciones Introductorias}

La crisis existencial que experimenta el proyecto europeo está permitiendo que se suscite un sugerente y positivo debate sobre el futuro de Europa y sus límites. Lo deseable es que este período de reflexión culmine con un renovado impulso a la construcción europea y logre poner fin a la crisis de identificación de la ciudadanía con el proyecto europeo ${ }^{1}$.

El contexto europeo actual aporta argumentos adicionales importantes a favor de una necesaria profundización y avance en nuestro proyecto europeo común como solución frente al errático devenir que podría derivarse de una atomización nacional de respuestas estatales territorializadas. Más que nunca es el tiempo de la política y en particular de la política europea.

La construcción de esta Europa unida está resultando una tarea compleja y apasionante, no exenta de enormes dificultades y obstáculos, tal y como sucede en el momento actual. Con frecuencia se acusa a los europeístas de ingenuos perpetuadores de utopías irrealizables y en estos momentos de cierta zozobra del proyecto y ante el nivel y la complejidad de las decisiones a adoptar la opción más defendible es la de mantener el ánimo europeísta con una decidida voluntad e impulso favorable a una mayor profundización en la integración europea, priorizando la dimensión supranacional sobre la intergubernamental ${ }^{2}$.

Es el momento de ser críticamente constructivo con la evolución un tanto desnortada del proyecto europeo. Vivimos en una época de transformación radical de nuestros marcos de referencia provocada por una nueva realidad globalizadora emergente. Los Estados ya no tienen capacidad para abordar unilateralmente todos los problemas derivados de este complejo mundo ni pueden resolver el conjunto de las necesidades de los ciudadanos ${ }^{3}$. La Unión

${ }^{1}$ Sobre el particular, vid., Susana Sanz Caballero, «Algunos signos de déficit democrático en el Tratado Constitucional Europeo y en su Carta de Derechos Fundamentales», en $L a$ Constitucionalización del proceso de integración Europea, AAVV, (Escuela Diplomática, Madrid, 2005), pp.273-289.

${ }^{2}$ Uno de los grandes europeístas del siglo pasado, el filósofo José Ortega y Gasset, expresó en una conferencia pronunciada en Berlín en el año 1949 (De Europa meditatio quaedam) su idea y su concepción de la entonces proyectada Europa política, al señalar que «Es, pues, un estricto error pensar que Europa es una figura utópica que acaso en el futuro se logre realizar. No; Europa no es sólo ni tanto futuro como algo que está ahí ya desde un remoto pasado; más aún, que existe con anterioridad a las naciones hoy tan claramente perfiladas. Lo que sí será preciso es dar a esa realidad tan vetusta una nueva forma». [José Ortega y Gasset, Meditación de Europa y otros ensayos (Madrid: Alianza Editorial, 2015), 48; 71-72; 128; 133-134; 141; 159].

${ }^{3}$ En tal sentido, vid., Daniel Innerarity, La democracia en Europa (Barcelona: Galaxia Gutenberg, 2017), p.37, al señalar que el proceso de integración europea es una de las más 
Europea debe ser, por ello, la respuesta de estabilidad política, prosperidad económica, solidaridad y seguridad a las inquietudes y convulsiones que genera la globalización.

Europa se enfrenta a uno de los desafíos más ilusionantes de toda su Historia: construir un nuevo modelo de convivencia política, una nueva forma de democracia transnacional que, más allá de la mera yuxtaposición de los sistemas políticos actuales, sea capaz de acoger y desarrollar una nueva sociedad basada en la libertad, la igualdad, la equidad, la solidaridad, la justicia social, la diversidad y el desarrollo sostenible.

Solo si revisamos con objetividad los logros alcanzados en estos ya más de sesenta años de andadura europea será posible sentar las bases que hagan posible la superación de la crisis institucional y de falta de liderazgo que estos momentos caracteriza al proyecto europeo. La crisis ha gripado el motor de la solidaridad europea. Cada vez es más tentador (y peligroso para nuestro futuro colectivo) pensar en el sálvese quien pueda, en el retorno al proteccionismo, en la autarquía. Por eso, más que nunca, hemos de echar la mirada atrás y pensar para qué nació Europa, qué objetivos perseguíamos ${ }^{4}$.

Debemos dejar a un lado la elección simplista a los que algunos quieren reducir la reflexión sobre Europa: o un Estado federal o una zona de libre cambio. Para salir de este atolladero necesitamos volver a elaborar una Constitución para Europa que combine la búsqueda de la integración con el pragmatismo y que se relegitime funcionalmente mejorando la vida y el futuro de los ciudadanos europeos.

interesantes manifestaciones de un problema general en las sociedades contemporáneas, concretado en resolver cómo reconstruir la autoridad política para hacer frente a los nuevos desafíos de la vida común.

${ }^{4}$ Así, es muy relevante para tener presente qué supone el proyecto de la Unión Europea traer a colación unas palabras de Antonio Moreno Juste y José Luis Neila Hernández: «Europa acabó el siglo XX con una estabilidad y prosperidad sin precedentes. Atrás habían quedado las guerras, las dictaduras y los tiempos de odios, superados la mayoría de los conflictos étnicos y disputas territoriales que la habían conducido al abismo entre 1939 y 1945; la consolidación de la democracia fue acompañada de notables avances económicos, derechos civiles y libertades; los ciudadanos dejaron de estar discriminados por su raza, género o condición y disfrutaban de un amplio sistema de beneficios sociales. Ciertamente, como afirma Julián Casanova "no era el paraíso, pero comparado con el pasado y con lo que se veía en otros continentes, muchos tenían la sensación de estar viviendo en el mejor de los mundos posibles" ». Y un poco más adelante señalan que "Para los europeos que vivieron la Segunda Guerra Mundial, la construcción europea representó durante décadas las ideas de paz, solidaridad y reconciliación. Posteriormente, aquéllos que vivieron dictaduras durante la segunda mitad del siglo XX, sintieron que esa Europa representaba el ideal de la democracia, progreso económico y modernidad social». [Antonio Moreno Juste y José Luis Neila Hernández, «Europa tres décadas después de la caída del Muro», Revista de Occidente, n. ${ }^{\circ} 418$ (2016): 47-48.]. 
Todo ello plantea la exigencia y el reto del liderazgo político y permite reivindicar el protagonismo de Europa y de sus instituciones: es el momento de reconquistar el futuro alejado de una mera suma de expectativas individuales, desligadas de realizaciones colectivas ${ }^{5}$.

Este momento de zozobra es en realidad una oportunidad y un reto para la UE, y la respuesta a esta cuestión debe comenzar por una evidencia: la impotencia de los Estados-Nación frente a las consecuencias de la globalización. Es la hora de apostar más por la UE, porque el diseño institucional y las herramientas de que disponen los Estados devienen por sí solos insuficientes para hacer frente a las dinámicas desencadenadas por los mercados globales.

La petición o propuesta de más Europa no ha de ser hueca sino que debe traducirse en generar un clima de confianza recíproca interestatal que culmine en una mayor atribución competencial a las instituciones europeas, necesaria para liderar una nueva y auténtica política financiera EuropeoComunitaria como base para evitar caer en el futuro en los mismos errores del pasado.

Europa es, pese a sus defectos e imperfecciones, una potencia emergente y constituye nuestra referencia institucional, motor de nuestras reformas internas modernizadoras y fuente primordial de nuestro Derecho. Europa debe basarse en la profundización de la cultura, la educación, la solidaridad, los valores democráticos y los principios que inspiraron la Declaración Universal de Derechos Humanos. La Historia demuestra que aquellas instituciones o estructuras que han basado su poder en una relación exclusiva de superioridad o dominio han terminado por fenecer tarde o temprano. Por el contrario, los ideales y los valores terminan calando lenta pero inexorablemente en la sociedad, generando un vínculo indestructible con el progreso de la humanidad.

Europa debe responder a los retos del siglo XXI con valentía y de forma innovadora. En estos tiempos de incertidumbre, la UE se encuentra en una situación inmejorable para impulsar a escala mundial una nueva organización social y política basada no ya en intereses, sino, sobre todo, en valores. Nunca había coincidido en un espacio geográfico tan reducido

${ }^{5}$ En tal sentido, vid., Innerarity, La democracia... pp.17-18, al explicar que se debe dejar a un lado la elección simplista a los que algunos quieren reducir la reflexión sobre Europa: o un Estado federal o una zona de libre cambio. La idea de proporcionar un relato para la Unión Europea sugiere explicar lo que es inevitablemente complejo de un modo arbitrariamente simple. Si así fuera, lo que obtuviéramos en términos de popularización lo perderíamos en exactitud. No habríamos ganado nada si lo comprendido y aceptado fuera algo sustancialmente diferente de lo que tenemos que relatar. Este es el nudo de nuestro problema y cuanto antes lo reconozcamos menos expuestos estaremos a las simplificaciones populistas o tecnocráticas. 
un desarrollo socioeconómico, una consolidación democrática y una diversidad cultural tan extraordinarios como los que se dan actualmente en la Unión Europea ${ }^{6}$.

Necesitamos un renovado pacto constitucional europeo respetuoso con todos los derechos fundamentales y que otorgue un protagonismo real tanto a las personas y organizaciones de la sociedad civil europea como a las entidades que conforman esa realidad plural y diversa que es Europa. Un Acuerdo que reconozca la existencia de demos políticos intermedios entre el ciudadano y el Estado. Una Europa que en el momento actual debate acerca de la redefinición de sus objetivos no puede dejar pasar por alto el importante papel de las regiones, que han de ser agentes activos, dinámicos y capacitadas para acercar el proceso de integración a una ciudadanía cada vez más apática sobre una Europa demasiado alejada de sus realidades políticas y culturales.

A pesar de los desencuentros puntuales y de momentos de estancamiento, la Unión Europea viene configurándose como un proyecto de paz, libertad y justicia social, una defensora de la multilateralidad y del diálogo entre culturas en los escenarios políticos mundiales, un espacio de bienestar y compromiso social que apuesta por la cooperación con los países más débiles y líder mundial en la lucha contra el cambio climático. Por todo ello es prioritario que la Unión Europea asuma un mayor protagonismo como actor global en el escenario internacional.

Más allá de la unión política y del mercado único, la Unión Europea es también y sobre todo una comunidad de valores. La Carta de Derechos Fundamentales de la Unión Europea garantiza a la ciudadanía europea el ejercicio de sus derechos y libertades fundamentales.

El Tratado de Lisboa recoge como valores fundamentales de la UE el respeto a la dignidad humana, la libertad, la democracia, la igualdad y los

${ }^{6}$ Efectivamente, como bien subraya la profesora Araceli Mangas Martín, «Somos el siete por ciento de la población mundial, generamos el veinte por ciento de la riqueza, y los veintiocho Estados, junto con la UE suponen el cincuenta por ciento del gasto social total mundial, en educación, sanidad, ayudas y prestaciones sociales, ayuda humanitaria.... Es decir, en igualdad y solidaridad. Veintiocho Estados hacen tanto como el resto del mundo». Por ello, a continuación expresa que «Tengamos, pues, el valor de estar orgullosos de nuestros propios logros, que han convertido a nuestro continente en el mejor lugar del mundo y en el mejor momento de la historia de los seres humanos. Tengamos el valor de oponernos a la retórica de los demagogos que afirman que la integración europea sólo beneficia a las élites, que la gente corriente sólo ha sufrido como consecuencia de ella y que los países saldrán adelante mejor en solitario que unidos. No hay sustituto ni alternativas para la igualdad, la libertad y la solidaridad en el seno de la Unión. Y ningún sistema, ninguna alianza o Estado aislado se puede cerrar al mundo moderno sin conocer el fracaso o el colapso». [Araceli Mangas Martín, «Postbrexit. Entre la Unión Europea necesaria y la posible», Revista de Occidente, n. $^{\circ} 440$ (2018): 61.]. 
derechos humanos y establece que la Unión tiene como finalidad promover la paz y el bienestar de sus pueblos. Se trata de principios legalmente vinculantes que los Estados miembros están obligados a observar. La UE apoya el objetivo de desarrollar y consolidar la democracia y el Estado de Derecho $\mathrm{y}$ el respeto de los derechos humanos y las libertades fundamentales ${ }^{7}$.

Igualmente la solidaridad y la cooperación al desarrollo son dimensiones clave que la UE impulsa en su política exterior para propiciar una Europa abierta, solidaria y sostenible, más cercana a las necesidades de la ciudadanía y que trata de dar respuesta a los desafíos globales.

La UE ha de asumir plenamente su responsabilidad en una gobernanza global. Y cabría proponer una Unión Europea comprometida con el multilateralismo, que lidere el tránsito hacia un nuevo orden mundial basado en reglas fijadas de común acuerdo y que garantice los derechos humanos, el desarrollo sostenible y el acceso al patrimonio común universal.

Hay que avanzar hacia una UE abierta, capaz de dar respuesta a los desafíos globales y respetuosa con los consensos internacionales alcanzados en materias como los derechos humanos, el cambio climático o el desarrollo humano sostenible. La UE debe responder al patrón de potencia que implementa la globalización de manera ética, aunando solidaridad y desarrollo humano sostenible.

7 Según la profesora Araceli Mangas Martín, para lograr el citado objetivo resulta imprescindible una Unión Europea ejemplarizante en la defensa en el seno de los Estados miembros tanto los Derechos Humanos como del Estado de Derecho. Ello se debe a que en los últimos tiempos, desafortunadamente, la propia UE se ha relajado a la hora de observar el cumplimiento de los «criterios de Copenhage» por parte de los nuevos Estados miembros que ingresan. En otras palabras, hoy en día existe pasividad ante violaciones graves y sistemáticas de tanto los Derechos Humanos como del Estado de Derecho. A título de ejemplo, por un lado, en Polonia se conculca la libertad de expresión, la libertad de reunión y el derecho a la intimidad y, por otro lado, en Hungría se ha restringido la libre circulación de capitales. La permisividad de ello, según la autora, no tiene nada que ver con la firmeza con la que se actuaba en los años 1999 y 2000 contra Austria. Por ello, indica que «Europa parece indiferente o simplemente reniega en relación con esos países de algunos derechos humanos». Y a renglón seguido opina que «Necesitamos cumplir con los deberes internos de respeto y promoción de los derechos humanos, rearmarnos moralmente de los valores que hemos explicitado en los artículos 2 y 3 de del Tratado de la UE para recuperar la credibilidad entre la población, en especial los más jóvenes, para frenar los populismos dentro y poder ser influyentes fuera. En la próxima revisión de los tratados - después de 2019 o más adelante - también podría ayudar, en casos así, una reforma completa del artículo 258 del TFUE de modo que, en el marco de ese procedimiento por infracción, la Comisión Europea pueda ejercer una acción contra un Estado miembro que ha cometido una violación grave y sistemática de los derechos fundamentales». Junto a lo anterior, también considera la autora que la UE debe ser pionera en el desarrollo de nuevos Derechos Humanos para adaptarse a la sociedad actual como, por ejemplo, el derecho al olvido y los derechos relacionados con la innovación de la tecnología digital (referentes a la privacidad y la seguridad principalmente). [Mangas Martín, «Postbrexit. Entre la Unión Europea necesaria y la posible», 43-46.]. 
Combinar ética y comercio internacional es posible; para ello resulta preciso que tanto en la negociación como en la posterior implementación de los acuerdos con terceros países por parte de la UE se promueva la competitividad y capacidad generadora de empleo de la industria europea, y particularmente de las pymes, se garantice la adecuada reciprocidad, así como el mantenimiento y la promoción de los estándares europeos en materia de derechos sociales y laborales, derechos de los consumidores, protección del medio ambiente, protección de la propiedad intelectual y de datos y de la diversidad cultural. Así está mostrándose en recientes Acuerdos comerciales como el alcanzado con Vietnam.

En particular, la UE deber evitar el dumping social y las deslocalizaciones e incorporar en sus Acuerdos comerciales e inversión sistemas de tribunales de inversiones de carácter público.

De igual modo cabría proponer que se redoble el esfuerzo en cooperación al desarrollo tanto por imperativo ético como desde el convencimiento de que la lucha contra la pobreza y la desigualdad es factor de seguridad y estabilidad.

Es el momento de reivindicar una Unión Europea que acoja frente a una UE fortaleza. La UE debe garantizar los derechos fundamentales de las personas que huyen de la pobreza, las guerras, la persecución o las violaciones de los derechos humanos y llegan en busca de refugio.

La respuesta a la crisis de las personas refugiadas así como al fenómeno la inmigración ilegal demanda de una actuación integral que aborde las múltiples dimensiones de estas realidades: situaciones de amenaza y pobreza extrema en los países de origen y tránsito, lucha contra las mafias, controles en frontera, condiciones de acogida, así como el establecimiento de un marco legal que posibilite el reasentamiento en la UE con carácter permanente de personas necesitadas de protección internacional, con especial atención a los colectivos más vulnerables como los menores no acompañados ${ }^{8}$.

Cabría explorar fórmulas innovadoras que permitan la llegada a suelo europeo-comunitario de personas necesitadas de protección internacional por vías seguras y accesibles, tales como la reunificación familiar ampliada,

${ }^{8}$ En tal sentido, vid., Daniel Gamper. «Europa: entre la realidad negativa y la aspiración moral». En ¿Dónde, vas Europa?, editado por Miquel Seguró y Daniel Innerarity. (Barcelona: Herder Editorial, 2017), pp. 101-113, añade que los refugiados tienen derecho a que sus demandas sean debidamente procesadas y, en el caso de que sean aceptadas, deben ser acogidos y dotados de los derechos de la ciudadanía. La historia de la opresión y uniformización religiosa y cultural de los pueblos europeos se ve de esta manera negada por una Europa que se entiende a sí misma por oposición a su propia historia y que, por lo tanto, debe violentar su connatural tendencia centrípeta, la cual se alimenta de la lógica perversa de la democracia de masas. 
la puesta en marcha de corredores humanitarios o los programas de patrocinio comunitario ${ }^{9}$.

Este deseo de finalizar con éxito el proceso no es sin más un capricho intelectual de los impulsores de esta nueva etapa. Queda unida a una filosofía de mayor transparencia, de cercanía al día a día y a las preocupaciones cotidianas de los ciudadanos europeos que ha de avanzar en relación a tres grandes temas de reflexión:

- El desarrollo y la evolución económica y social de Europa (y en particular, el debate acerca de los valores comunes que inspiran el modelo social europeo),

- La percepción de la UE y sus funciones (profundizar en un discurso que ponga de manifiesto las ventajas concretas que aporta la pertenencia a la $\mathrm{UE})^{10}, \mathrm{y}$

- La reflexión pendiente sobre las fronteras de Europa y su papel en el mundo.

Tal y como acertadamente subrayó en su momento el Dictamen del Consejo Económico y Social Europeo (DOCE de 17-3-2006), hay que desarrollar una democracia participativa sustentada en dos pilares: diálogo civil y diálogo social reforzado en Europa. Es preciso adoptar medidas con-

${ }^{9}$ En relación con las personas en busca de refugio, la profesora Araceli Mangas Martín expresa en su trabajo que la crisis de los refugiados ha causado una profunda perturbación y desconfianza por la pasividad de las instituciones de la UE ante ella. Es cierto - continúaque existen proyectos para una reforma del asilo tanto en las propuestas de la Comisión como del presidente Macron como es la creación de una Agencia u Oficina de Asilo, así como que desde finales del año 2016 hay una policía y guardacostas europea de fronteras. Pero, a juicio de la Profra. Mangas, «necesitamos una mayor integración de las políticas de migración mediante una mejora sustancial de la conectividad de datos y ficheros o de los documentos de identidad para asegurar un control efectivo de las fronteras exteriores que permita la recuperación de la libertad de movimiento entre los Estados miembros». [Mangas Martín, «Postbrexit. Entre la Unión Europea necesaria y la posible», 51.]. Asimismo, para reforzar la reivindicación de una UE acogedora, solidaria y defensora de la dignidad de cualquier persona, resulta de gran interés recordar aquí que ya a comienzos del siglo XVI Francisco de Vitoria, a través de la primordial labor que desarrolló en la Escuela del Derecho de Gentes de la ocho veces centenaria Universidad de Salamanca, consideraba la prohibición a los extranjeros de viajar por cualquier territorio o de habitarlo permanentemente como atentatoria al citado Derecho de Gentes.

${ }^{10}$ En tal sentido. vid., Innerarity, La democracia... p.82, al aclarar que Habermars define el déficit democrático del Estado-nación de un modo muy específico y plausible. Los Estados-nación ya no están en condiciones de cumplir lo que sus sociedades esperan de un gobierno democrático. La erosión de su poder se debe a la creciente interdependencia y a la dinámica de la globalización. Ambos aspectos son razones imperiosas para cooperar transnacionalmente y transferir competencias a las instituciones supranacionales... Mientras esta transferencia no lesione los procedimientos democráticos, puede servir para rescatar el constitucionalismo democrático. La UE representa ese potencial. 
cretas para lograr una mayor participación directa de los ciudadanos en el proceso político a escala de la UE y materializarla mediante una propuesta normativa encaminada a reforzar jurídicamente el derecho de iniciativa de los ciudadanos europeos.

Ahora es más importante que nunca desarrollar el concepto de ciudadanía de la UE como una ciudadanía activa, y, como señala también en otro reciente Dictamen el propio CES Europeo (2006/C 65/22) ha de ser una ciudadanía de mayor calidad, más abierta, igualitaria e integradora, sin ninguna discriminación.

La clave radica en lograr un balance equitativo y adecuado entre las tres dimensiones (libertad, seguridad y justicia) para no dañar los valores fundamentales (derechos humanos y libertades públicas) y principios democráticos (Estado de Derecho) compartidos en toda la Unión ${ }^{11}$.

¿Es Europa una potencia en decadencia o emergente?; ¿Representa Europa como construcción política un modelo de sociedad, que, pese a sus defectos e imperfecciones, merezca la pena ser defendida?; ¿Ha olvidado esta Europa política que su verdadera razón de ser somos los ciudadanos?; Europa suscita más interrogantes que respuestas, porque vivimos en una época de transformación radical de nuestros marcos de referencia, provocada por una nueva realidad globalizadora emergente. Los Estados ya no tienen capacidad para abordar unilateralmente todos los problemas derivados de ese complejo mundo ni pueden resolver el conjunto de las necesidades de los ciudadanos. La Unión Europea ha de representar, por ello, la respuesta de estabilidad política, prosperidad económica, solidaridad y seguridad a las inquietudes y convulsiones que genera la globalización ${ }^{12}$.

11 Vid., Joxerramon Bengoetxea, «Informe sobre Derechos Fundamentales y Ciudadanía europea en el Tratado constitucional», en La Constitución Europea. Una visión desde Euskadi, AAVV, (Eurobask, 2005), pp.17-23

${ }^{12}$ La profesora Araceli Mangas Martín nos indica a este respecto que la UE ha resultado ser una institución fundamental a la hora de encarar la realidad globalizadora de nuestros días. En efecto, la globalización - nos dice - ha sido un fenómeno imparable de apertura, liberalización, privatización y desregulación ante la cuarta revolución industrial-tecnológica que ha tenido, no obstante, consecuencias muy beneficiosas. En este sentido, la existencia de la UE, y más específicamente de la defensora de los Tratados que es la Comisión Europea, ha sido fundamental para hacer frente, por un lado, a la reiterada violación de obligaciones fiscales y de normas de leal competencia y, por otro lado, al abuso de posición dominante por parte de los más grandes de la tecnología. Efectivamente - continúa la autora - se ha sancionado o abierto expediente a Microsoft por más de 1.500 millones de euros, a Amazon por 250 millones de euros, a Apple por 13.000 millones de euros, y a Google por 2.424 millones de euros. Sin embargo, aún quedan por corregir y afrontar algunas cuestiones muy importantes como, por ejemplo, los beneficios asimétricos en el comercio y en las inversiones; el hecho de que los asiáticos puedan acceder al mercado europeo fácilmente, con rapidez y seguridad, mientras que los europeos encuentran muchas trabas e inseguridades para acceder al mercado asiático; y la disminución de las clases medias europeas que las ponen en riesgo de caer en el de- 
No existe un «demos» europeo, y sin embargo el poder y el fundamento de la democracia reside en la ciudadanía. Resulta llamativo que el año 2013 fuese calificado por la Comisión Europea como «Año Europeo de los ciudadanos»; ¿Debe existir un año dedicado a la ciudadanía europea?; ¿Significa eso que los anteriores o posteriores postergan al verdadero protagonista de la construcción europea?.

El Prof. Daniel Innerarity ha reflexionado recientemente sobre la falta de sincronía entre los sistemas sociales (y particularmente entre el tiempo de la economía y el tiempo de la política). La política exige reflexión, discusión, debate, y las innovaciones en otros ámbitos discurren a un ritmo vertiginoso. Ese desajuste entre las esferas económica y financiera, que trascurren a ritmo de alta velocidad y la política no debe servir para «demonizar» la respuesta política. Al contrario: una sociedad sin debate político será siempre una sociedad menos libre y menos justa.

Sumidos en un contexto de desconcierto respecto al futuro andamiaje institucional de la Unión y cómo solventar la crisis de identidad europea ${ }^{13}$, es preciso reflexionar sobre los costes de la «No Europa». ¿Qué ocurriría si no existiera Europa y volviésemos a la suma de autarquías estatales?. Trataré de aportar reflexiones para el debate sin una excesiva carga doctrinal, en la confianza de que solo si revisamos con objetividad los logros alcanza-

letéreo populismo. Es por ello - sigue la autora - que la propia Comisión Europea realizó el 10 de mayo de 2017 la «Reflexión sobre el encauzamiento de la globalización» donde reconoce la necesidad de «reescribir el código normativo mundial de forma que el libre comercio pase a ser comercio justo» y de «actuar con decisión contra las prácticas desleales». Tras ello la autora expresa que «Necesitamos una UE protectora porque muchos países en Asia no comparten las exigentes normas en materia de empleo, seguridad y medio ambiente y hacen dumping social y medio ambiental». Y que «La misma Comisión reconoce que necesitamos una UE protectora fomentando valores y estándares rigurosos en terceros países y protectora de los ciudadanos europeos frente a las prácticas desleales». Finaliza diciendo que «la ingenuidad del libre mercado unilateral tiene que transformarse, y es posible, en una Unión protectora que se base en una vieja norma del derecho internacional, el principio de reciprocidad, en el tratamiento del comercio y las inversiones europeas en el exterior». [Mangas Martín, «Postbrexit. Entre la Unión Europea necesaria y la posible», 46-49.].

${ }^{13}$ Es preciso señalar que, desafortunadamente, la crisis de la identidad europea es un déficit que lastra Occidente desde hace mucho tiempo. En efecto, como bien indican Antonio Moreno Juste y José Luis Neila Hernández en su trabajo, «la creciente convergencia interna y homogeneización producida en Europa desde 1945 no ha venido acompañada de un sentido de identidad europea más común y ampliamente aceptado. Es más, la tan anhelada identidad europea desde los años ochenta ha devenido en un mosaico formado por muchas piedras diferentes dentro de patrones más amplios, en lugar de convertirse en una alfombra tejida con grandes manchas de color: a pesar de algunos valores fuera de determinados círculos de gran movilidad en ciertos grupos económicos, profesionales y políticos, los europeos carecen, en su gran mayoría, de un sentido de identidad común». [Moreno Juste y Neila Hernández, «Europa tres décadas después de la caída del Muro», 37]. 
dos en estos ya más de sesenta años de aventura Europeo/Comunitaria será posible sentar las bases que hagan posible la superación de la crisis institucional y de falta de liderazgo que estos momentos caracteriza al proyecto europeo.

Todos los dirigentes europeos hablan de la necesidad de cambiar la UE pero discrepan en el diagnóstico y en el proceso de reforma o refundación que debe seguirse para relegitimar una nueva Europa. Y al final no cambiar nada parece seguir siendo la mejor forma de satisfacer a todo el mundo. ¿Cuál ha de ser el puerto de destino para esta Europa sin alma?.

Si la UE quiere sobrevivir, sus representantes deberían dejar claro cuál es su objetivo. Seguir sin rumbo, como hasta ahora, sacrificando la integración en beneficio de la ampliación no es el camino. Tampoco pasa su futuro, probablemente, por convertirse en una federación (difícilmente habrá alguna vez consenso unánime, necesario conforme al Tratado de Lisboa para su reforma, en torno a esta idea federalizante) ${ }^{14}$, sino en una Unión dotada de una Constitución, orientada hacia el exterior, que proteja y potencie su diversidad, que admita realidades políticas más allá de los Estados y que delimite bien su ámbito de integración territorial.

\section{Europa: entre lo intergubernamental y lo supraestatal}

Europa camina a la deriva, sin rumbo. La crisis ha gripado el motor de la solidaridad europea. Cada vez es más tentador (y peligroso para nuestro futuro colectivo) pensar en el sálvese quien pueda, el retorno al proteccionismo, a la autarquía. Por eso, más que nunca, hemos de echar la mirada

${ }^{14}$ Lo cierto es que dicha idea federalizante ha sido de poca raigambre en la sociedad europea como bien indican David Ramiro Troitiño y María de la Paz Pando Ballesteros en su trabajo. Así, nos hacen recordar que Winston Churchill «expresó su negativa a la propuesta federal para Europa en el Albert Hall de Londres, en mayo de 1947, en una reunión del Movimiento Europeo. No era Churchill el único contrario a la idea de una Federación Europea ya que la mayoría de los ciudadanos europeos estaban, y siguen estando, en contra de esta idea. El propio Altiero Spinelli (1983), un notable federalista, mantenía un planteamiento radical al respecto, con la finalidad de erosionar la resistencia popular en la construcción de una Federación Europea. Para este padre de Europa, la federación debería haber sido implementada desde arriba y sin el consentimiento de los europeos, quienes con el tiempo reconocerían sus efectos benignos y apoyarían el proyecto. Churchill, por el contrario, delegaba la toma de dicha decisión en los propios europeos para evitar costes y desgastes políticos. En su discurso de apertura en el que presentó el proceso de contrucción europea, en el Congreso de Europa, en mayo de 1948, añadió que: "debería consistir en el movimiento de la gente, no de los partidos" ". [David Ramiro Troitiño y María de la Paz Pando Ballesteros, «El modelo de integración europea de Churchill», Revista de Occidente, n. ${ }^{\circ} 434$ (2017): 63]. 
atrás y pensar para qué nació Europa, qué objetivos perseguíamos con nuestro soñado proyecto europeo.

De forma brillante el prof. Gurutz Jauregui definió tres modelos o sistemas que han triunfado a lo largo de la historia, que han logrado geopolíticamente imponer su supremacía. Europa debe decantarse por alguno de ellos: el primer ejemplo vino históricamente aportado por el viejo imperio romano. Logró, por el peso de su supremacía militar, imponerse a base de conquistas. La forma moderna de esta supremacía estuvo representada por EEUU en la era del presidente Bush, anclada en el unilateralismo y en el uso brutal de su poderío militar despreciando la legalidad internacional: ¿Alguien se acuerda hoy de Irak o Afganistán?;

El segundo modelo de dominación geopolítica del mundo vino representado por los fenicios: florecieron gracias a las relaciones comerciales, y lograron imponer su modelo al mundo mediante su abrumadora supremacía comercial. Hoy día los Estados del sudeste asiático (China, India, entre otros) representan la versión moderna de ese modelo de primacía mundial.

Y ¿Europa? ni podemos ni queremos asociarnos al modelo de liderazgo basado en la fuerza militar ${ }^{15}$, ni desde luego podemos pretender competir

15 Como muy bien nos señala la profesora Araceli Mangas Martín en su citado trabajo, la prioridad de la Política Común de Seguridad y Defensa asumida por la UE ha de ser la seguridad de los ciudadanos y ciudadanas europeas (más aún con la más que probable salida del Reino Unido de la UE). En efecto, «los europeos somos conscientes de que la integración es un bien común, un bien imprescindible para nosotros y un global public good para la comunidad internacional», y ello es lo que hemos de defender. Es por ello que expresa que «La propuesta francesa de una fuerza de intervención común (fuerza de defensa operacional en el proyecto Juncker), junto a un presupuesto de defensa común y un fondo europeo de Defensa es un gran proyecto de futuro». Continúa explicando que «necesitamos soluciones europeas y capacidades europeas para la seguridad y la defensa» porque «La ciudadanía europea exige respeto a nuestros valores, preservar nuestro modo de ser y de vivir, así como la independencia e integridad de nuestros Estados. Sin seguridad no cabe ni la libertad ni la prosperidad. La seguridad y defensa no se garantiza de forma aislada por un Estado, ni siquiera por los mejor dotados militarmente». Finaliza precisando que «la acción militar será necesaria sólo en casos extremos con evaluaciones muy exigentes sobre consecuencias y proporcionalidad», y que «o nos ocupamos juntos del entorno o el entorno se ocupará de nosotros». [Mangas Martín, «Postbrexit. Entre la Unión Europea necesaria y la posible», 42; 52-54.]. Asimismo, también son muy interesantes a este respecto las indicaciones de Antonio Moreno Juste y José Luis Neila Hernández realizadas en su trabajo. Así, por un lado, nos señalan que la naturaleza de la seguridad se caracteriza por su multidimensionalidad y su globalidad. Y, por otro lado, traen a colación unas palabras de Celestino del Arenal donde se identifica como una idea caduca la de que «la seguridad es exclusivamente una función del poder nacional o de la fuerza militar y económica. En la búsqueda de soluciones al problema de la inseguridad, los Estados deben afrontar con mayor frecuencia circunstancias fuera de control, como crisis económicas estructurales y tendencias económicas, demográficas, ambientales y financieras a las que sólo puede darse solución mediante acciones comunes y solidarias».[Moreno Juste y Neila Hernández, «Europa tres décadas después de la caída del Muro», 40-41]. 
con los reyes del todo a cien: reducir salarios, despedir empleados, abaratar costes de producción no nos hace en realidad más competitivos, sino que acaba con el modelo social europeo y nunca van a posibilitar que compitamos con el dumping social que practican los asiáticos.

¿Dónde debe ubicarse Europa? en el tercer modelo histórico de dominación geopolítica del mundo: el de la ahora denostada Grecia: la Grecia de los valores, de la democracia, de los derechos, de los principios democráticos. Podemos y debemos ahondar en este modelo, sin desnaturalizar nuestro sistema de protección social ${ }^{16}$.

La política ha de ocupar el primer plano de las decisiones económicas, y pese a que la clase dirigente europea tiene problemas para atender en tiempo real a cada una de las consecuencias derivadas en serie de esta crisis, debido probablemente a que hasta el momento han buscado las causas de la misma exclusivamente en el sistema financiero, hay que elaborar reglas que hagan primar la democracia sobre los mercados. Por todo ello, más que nunca, es el tiempo de la política, es hora de hacer política de verdad para ganar el pulso a los mercados. Nuestro futuro (y la superación de este duro presente) depende de ello.

${ }^{16}$ Resulta de gran interés transcribir aquí otras reflexiones del filósofo José Ortega y Gasset acerca de Grecia y del clasicismo. En este sentido, expresó en su trabajo rubricado «Sobre los estudios clásicos» que «el hombre nació en Grecia», y que tras el vocablo clasicismo «alienta místicamente la realidad más granada y plenaria» pues tenía a lo clásico no sólo por el embrión de la cultura sino también por el sentido perenne de ella. Así, ahonda su explicación indicando que cultura «significa elaboración y henchimiento progresivo de lo específicamente humano» y que «Si no se puede apreciar la progresión, la palabra cultura no tiene sentido, y no se puede apreciar aquélla si no se supone una dirección, si no se tira una línea guión sobre la que luego hayan de marcarse los grados del avance». Un poco más adelante, completa su explicación indicando que «Esa línea magnífica que orienta la historia y pone en ristre los siglos hacia un ideal porvenir, necesita como toda línea de dos puntos para ser determinada: y el uno, el de oriundez, esta en Grecia, donde el hombre nació, y el otro, el de fenecimiento, está en lo infinito». Y precisa que «En la danza general de la vida inserta el clasicismo un gesto de dignidad, gracias al cual aquella danza burlesca se ordena en majestuosa teoría humana», así como que «Clasicismo sólo hay uno, clasicismo griego, y los renacimientos serán siempre, forzosamente, un volver a nacer de Grecia, un volver a abrevarse en la energía perenne de las ruinas helénicas». Igualmente, en otro trabajo suyo sobre el mismo tema rubricado «Teoría del clasicismo» expuso que consideraba el clasicismo decisivo en todo tiempo y que «si creemos en la cultura, tenemos que creer en el clasicismo, porque es éste, en mi entender, algo así como un principio de la conservación de la energía histórica». Asimismo, indicó que lo opuesto al clasicismo es el romanticismo, y que ambos han existido siempre de Grecia hasta nuestros días. Así, dice, «la historia europea, por otro nombre humana, es la historia de las luchas entre esos dos ángeles, Ormuz y Arimán, principios de lo bueno y de lo malo». Concluye señalando que «Hay en un pueblo tanta mayor cultura, cuantos más sean los temas ideales presentes en su conciencia», y que «Lo que ha sido, por el mero hecho de haber sido, renuncia a ser lo mejor». De esto último deduce que «esa lucha por mejorarse, por superarse, es la emoción clásica: y querer afirmar algo histórico como definitivo, sea un pueblo, sea un héroe, sea el propio yo, es la emoción romántica». [José Ortega y Gasset, Obras completas. Tomo I_1902/1915. (Sabadell: Taurus, 2017), 116-119; 120-126]. 
Pese a la desafección, la lejanía, la frustración, la indignación hacia la política europea, pese a todo, hay que exigir desde una rebelión cívica otra construcción europea, hay que apoyar a quien de forma sincera nos proponga una Europa más social, más abierta a la realidad de las naciones sin Estado, a la superación de los egoísmos estatales, a la potenciación de una verdadera Europa de los ciudadanos y de los pueblos europeos, superando el exclusivo protagonismo de los Estados.

La pregunta, más atinada que nunca, la realizaba recientemente Mark Leonard: ¿es posible construir una Europa sin europeísmo? ¿es posible avanzar hacia el federalismo sin federalistas?, preguntas a las que cabría añadir otra, clave: ¿se prepara solo una unión fiscal parcial, basada en parámetros de estabilidad y austeridad, o una unión plena, que comprenda además de los anteriores, los factores de solidaridad y transferencias?.

Los ciudadanos europeos nos debatimos entre la desafección y el malestar ante la forma de comportarse y de reaccionar frente a la crisis desde las instituciones europeas. No estamos en contra del proyecto europeo, sino de su actual rumbo. Es preciso reconstituir políticamente Europa. Hay que apostar por un liderazgo inequívocamente fuerte para reorientar bien la empresa común que representa Europa.

Suele afirmarse que Europa tiene problemas de comunicación. El mismo Jacques Delors calificó al proyecto europeo como un Objeto Político No Identificado. No debe sorprendernos demasiado comprobar que la percepción de la opinión pública es borrosa y confusa. Y ese déficit de imagen y de apoyo social no reside en una mera falta de comunicación que se pueda resolver sin más con una mejor campaña de marketing. Es una falta de comprensión y de convicción (entre sus ciudadanos y sus gobernantes) acerca de la originalidad, significación y complejidad de la construcción europea ${ }^{17}$.

Europa no es una potencia extranjera que nos invade, aunque así parecen explicarse los miedos de los ciudadanos y las escasas ambiciones de buena parte de sus dirigentes. Y así pasa con frecuencia que unos países parecen muy europeístas porque en el fondo aprecian las subvenciones que han recibido mientras que otros ven en Europa una amenaza y dejan de percibir la

17 En tal sentido, vid., Daniel Innerarity, entrevistado por Andrés Seoane, revista El Cultural. Entrevista publicada en la página web, 12 de mayo de 2017, https://www.elcultural. com/noticias/letras/Daniel-Innerarity-Debemos-comprender-la-naturaleza-de-la-UE-antes-decuestionarla/10769, al aclarar que ciudadanos y dirigentes tenemos dificultades en comprender, juzgar y actuar en los nuevos contextos. Hay un conjunto de discursos banales y malas prácticas que dificultan la comprensión del momento en el que vivimos y el papel que Europa tiene que jugar. Debilitadas las diversas legitimaciones de la integración, los únicos relatos poderosos que quedan en pie son las impugnaciones populistas, alimentados por ese juego perverso de «culpar a Bruselas» y, sobre todo, por la evidencia de que no estamos a la altura de los problemas que tenemos que gestionar. 
oportunidad que representa. Unos y otros tienen una percepción equivocada de lo que Europa representa y, mientras no se disuelva ese equívoco, la adhesión al proyecto político de la UE seguirá siendo débil o superficial.

No se puede avanzar en la integración política si no abordamos abiertamente la cuestión de la naturaleza de Europa, si escamoteamos las preguntas de fondo acerca de lo que es y puede llegar a ser. Comprender Europa es el primer paso para conferirle un sentido e imprimirle una dirección, para indicar a la ciudadanía el camino a seguir para superar esta tremenda crisis.

Pero Europa vive ahora en un ambiente de desencanto y desorientación. Esta crisis ha destruido muchas ilusiones sobre la solidez de su economía, incluso de su sistema monetario, como también sobre el papel que la Unión podría desempeñar en el escenario mundial.

La Unión Europea ha atravesado la crisis más grave de todas las conocidas desde la fundación de la CECA en 1951; la crisis financiera desatada en los EEUU aún no se había dejado sentir con toda su crudeza en Europa pero lo iba a hacer poco después, a partir de 2010, evolucionando hacia una crisis de deuda soberana que llegó a poner en entredicho la supervivencia del mismo euro y a sembrar dudas sobre la viabilidad y futuro del proceso de integración europeo.

No fue ésta la única situación muy compleja que tuvo que afrontar la Unión Europea, ya que la crisis humanitaria de las personas refugiadas ha puesto al descubierto las inconsistencias en la visión de los distintos Estados miembros. Finalmente, cuando empezaba a superarse la crisis económica que trajo como consecuencia unas tasas de desempleo, desigualdad y precariedad desconocidas en Europa en las últimas décadas, la Unión ha debido afrontar una nueva crisis carente de precedentes: por primera vez, un Estado miembro, el Reino Unido decidía en junio de 2016 abandonar la Unión Europea. No menos significativas son las cuestiones relativas al reto demográfico, al terrorismo de pretexto religioso ${ }^{18}$, los desafíos geopolíticos

18 Sobre este particular, la profesora Araceli Mangas Martínseñala que la lucha contra el terrorismo constituye un interés general y común de la UE y que, por ello, existe un deber explícito de solidaridad previsto en el artículo 222 TFUE. Asimismo, indica que las instituciones de la UE son cruciales para realizar con éxito esta lucha, así como para corregir los clamorosos fallos de seguridad que toda la ciudadanía europea ha percibido hasta ahora. En este sentido - continúa - sería deseable una mejoría de la cooperación policial y otorgar mayores poderes a Europol (hasta que pueda asumir las tareas de una fluida agencia de inteligencia e información) y Eurojust. Finalmente, la profesora subraya que la reación de la Fiscalía Europea para luchar contra el fraude fiscal «es una nueva oportunidad para mejorar la coordinación y persecución del delito». Y que «una vez eche a andar formalmente su jurisdicción, es muy probable que pudiera extenderse al terrorismo y la lucha contra el dilema de la delincuencia organizada, incluida la prevención y lucha contra la propaganda yihadista y de odio en Internet» al estar prevista esta posibilidad en el artículo 86.4 TFUE. [Mangas Martín, «Postbrexit. Entre la Unión Europea necesaria y la posible», 51-52.]. 
planteados por Rusia o el nuevo rumbo en la política exterior de los Estados Unidos de América.

Por otra parte, la sociedad internacional se enfrenta a un cambio de paradigma, con nuevos agentes ajenos a los Estados clásicos que irrumpen en la escena internacional y la emergencia de nuevos problemas y amenazas que no pueden ser resueltos por los Estados de forma aislada. En este contexto, la Comisión Europea planteó un debate sobre el futuro de la Unión Europea mediante la publicación del Libro Blanco sobre el Futuro de Europa el 1 de marzo de 2017.

El largo recorrido temporal de esta crisis nos muestra que con el recurso único a la política monetaria, por muy sólida y coordinada que ésta sea, no será posible salir de la misma o atemperar sus efectos. Ésta debe complementarse con medidas de pura política financiera, auténtico reto para Europa en estos momentos tan catárticos.

Desde su implantación en 1999 la Moneda Única supuso mucho más que un proyecto monetario. Representa una herramienta clave, troncal para la integración política de Europa. Se sabía que la Unión Económica y Monetaria no constituía un área monetaria óptima (al carecer de una fiscalidad común, de instituciones comunes y de una movilidad laboral mínima) pero la profunda crisis económica y financiera padecida ha puesto de manifiesto todas sus carencias.

En todo caso, y si bien durante la crisis se han producido progresos tanto en la arquitectura institucional como en la gobernanza de la eurozona o en la propia praxis monetaria, de cara al futuro se hace necesario desarrollar una política monetaria que persiga objetivos más amplios que la mera estabilidad de los precios.

Desde que el euro viera la luz no se ha producido una convergencia económica entre los doce países originarios más prósperos y los menos desarrollados. Sin embargo, eso no es achacable únicamente a la arquitectura del euro sino a la escasez de políticas presupuestarias. Por ello son necesarias otras medidas, además de significativos programas de inversión pública. Partiendo de esta base cabe solicitar que las reformas estructurales, socialmente sostenibles y necesarias para alcanzar una mayor productividad sean acompañadas de políticas de estímulo que permitan alcanzar la convergencia en renta y bienestar.

En el futuro y de nuevo atendiendo al horizonte de 2025 la Unión Económica y monetaria debería tratar de incorporar, de manera gradual, la realización de las siguientes medidas en los ámbitos de la gobernanza, la unión monetaria y la unión económica: Apostar por un verdadero «Gobierno Europeo responsable ante los ciudadanos europeos», es decir, una Comisión Europea que cuente con un o una presidenta elegido de entre los candidatos principales correspondientes a cada familia política, con una dirección eco- 
nómica del euro y un papel instrumental del BCE, con una posición fiscal común en las directrices económicas que se despliega con instrumentos de estabilización fiscal y no sólo de estabilidad financiera.

El Gobierno figuraría en la cúspide de la responsabilidad, fijando los objetivos de política económica a través de unas Grandes Orientaciones de Política Económica que adquirirían el carácter de un verdadero documento de programación económica-presupuestaria que sería aprobado por el Parlamento. En ese caso, las funciones del BCE deberían ser revisadas situando al mismo nivel los objetivos de la estabilidad de precios y el crecimiento y dando al Parlamento la capacidad de elegir al Consejo Ejecutivo de aquél.

Los objetivos de la UE, incluida la estabilidad financiera y el nivel de precios pertenecen a la esfera de la política y no deben dejarse en manos del BCE, sino del Gobierno, que es quien rinde cuentas a la ciudadanía.

El Parlamento Europeo debería jugar un papel fundamental en el funcionamiento y responsabilidad democráticos de las instituciones y organismos de la zona euro. El Parlamento Europeo debería incorporar, a través de las correspondientes revisiones de los Tratados, los mecanismos de votación necesarios para adecuar la acción de control únicamente a los representantes de los Estados miembros del euro. A partir de este embrión debería ser posible desarrollar un gobierno del euro.

De igual modo cabría solicitar la creación de la figura de Ministro/a del euro o del Tesoro Europeo asumiendo las funciones que hoy ejercen la presidencia del eurogrupo y el comisario de asuntos económicos y monetarios y reforzar el compromiso en la lucha contra los paraísos fiscales y el fraude fiscal como paradigma del hecho democrático.

En el ámbito de la Unión Monetaria cabría proponer como retos ineludibles los siguientes: completar la Unión bancaria incluido el establecimiento de Fondo de garantía de depósitos y crear un Tesoro de la zona euro mediante la emisión gradual de bonos europeos de manera que pueda invertir en proyectos europeos de interés común y alto valor añadido.

En el ámbito de la Unión Económica cabría proponer el establecimiento de un presupuesto propio y suficiente de la zona euro de carácter anticíclico que estimule la convergencia económica y social.

El documento de reflexión de la Comisión sobre el futuro de las finanzas de la UE pone en el centro del debate la cuestión del valor añadido europeo, que resume en alcanzar los objetivos establecidos en el Tratado y en «un presupuesto que prevé bienes públicos de dimensión europea o contribuye a defender nuestras libertades fundamentales, el mercado único o la Unión Económica y Monetaria».

El concepto del valor añadido europeo puede contribuir a romper la lógica del «justo retorno» que ha venido rigiendo las negociaciones de los 
Marcos Financieros Plurianuales. El presupuesto europeo debe aportar valor añadido en relación con la defensa de valores comunes europeos tales como la democracia, la libertad, el Estado de Derecho, los derechos fundamentales, la igualdad, la solidaridad, la sostenibilidad y la paz.

Y como medidas concretas cabría proponer que el presupuesto de la Unión se sitúe en el $2 \%$ del PIB de los veintisiete, una vez materializada, en su caso, la salida del Reino Unido de la UE, y todo ello bajo una estricta aplicación del criterio de subsidiariedad. Un presupuesto con capacidad de inversión en proyectos estratégicos para la Unión Europea que mantenga políticas orientadas a tener efectos redistributivos.

La propia Comisión europea ha defendido que tal incremento podría financiarse con un impuesto sobre las transacciones financieras y tasas medioambientales como las que recaen en las emisiones de CO2. Adicionalmente, los beneficios del BCE también podrían contribuir a dicha financiación.

Tal y como indican recientes documentos de reflexión de la UE, es necesario incorporar algún tipo de función de estabilización pudiéndose explorar «la protección de la inversión pública frente a la recesión económica y un régimen de seguro de desempleo en caso de aumento súbito de éste». En este sentido, se apuesta por introducir un componente de estabilización automática en el ámbito de una política fiscal mediante mecanismos vinculados a la evolución del desempleo y un Fondo de Estabilización Regional.

Junto a todo ello parece necesario apostar por el desarrollo de políticas e instituciones que fomenten el equilibrio de flujos comerciales y financieros en el seno de la UE, atenuar de este modo tanto los superávits como los déficits crónicos, y promover una evolución del Mecanismo Europeo de Estabilidad hacia un instrumento bajo la responsabilidad de la Comisión Europea con una capacidad financiera de 500.000 millones de euros. Este nuevo Fondo permitiría realizar actuaciones de emergencia en caso de nuevas crisis financieras. Todo ello debería venir acompañado de la materialización de la unión del mercado de capitales que posibilite una auténtica política económica compartida.

Para que la Política de Cohesión cumpla con los objetivos del artículo 174 del Tratado es necesario atender al cumplimiento de una serie obligada de premisas, entre las que cabría subrayar las siguientes: la UE debería incrementar sus dotaciones financieras de manera sustancial para que la política de cohesión actúe como instrumento contra-cíclico a través, por ejemplo, de niveles mínimos de inversión pública garantizados en las regiones con menor capacidad de resiliencia; de igual modo, la UE debería promover unos presupuestos sensibles al género y coadyuvar a la concreción de una genuina Europa Social destinando recursos al asegura- 
miento de unos estándares europeos básicos de carácter social que garanticen una vida digna.

Es necesario dotar de mayor protagonismo a las regiones tanto en la definición del alcance y contenido de la estrategia europea 2021-2027, como en su supervisión y aplicación a través del Semestre Europeo. En este proceso, la cooperación de las regiones es imprescindible para alcanzar los objetivos que marca la Comisión Europea en las recomendaciones específicas por país ${ }^{19}$.

Dado que los beneficios de la globalización están distribuidos de forma desigual tanto entre las personas como entre los territorios, es necesario acompasar la transformación económica provocada por la globalización y el cambio tecnológico a fin de que todas las personas y las regiones puedan contribuir al mercado interior y beneficiarse de él.

La complejidad y la magnitud de la crisis ha puesto de manifiesto estas carencias y realza la importancia de la dimensión Europea, que deriva en un factor clave al resultar más apropiada y eficaz que la suma atomizada de ámbitos estatales tradicionales. El desafío que supone para nuestra clase política y nuestra sociedad la dimensión de esta crisis aporta argumentos adicionales para apostar por Europa, una Europa abierta, no cerrada sobre sí misma.

La consecución de una Europa más democrática y más cercana a la ciudanía es una de las diez prioridades de la Comisión que preside JeanClaude Juncker. Una nueva Europa de veintisiete Estados emergerá previsiblemente el 30 de marzo 2019 y tras las elecciones al Parlamento Europeo de junio de 2019. La Comisión ha presentado una hoja de ruta para una Unión más unida, fuerte y democrática y en 2018 presentara sus propuestas relativas a las listas transnacionales a las elecciones de la UE, a la Fiscalía europea, a la Presidencia del Consejo Europeo y de la Comisión para reflejar la doble legitimidad de la UE así como ideas sobre cómo reforzar los principios de subsidiariedad y proporcionalidad y cómo mejorar la legislación.

Un aspecto estratégicamente clave para el futuro de la UE radica en hacer efectiva una gobernanza multinivel. La participación real de los go-

${ }^{19}$ Como bien indica el profr. Santiago Petschen, «Tener interés por las regiones no significa querer para ellas el máximo de atribuciones y de competencias. Lo importante para las regiones es que ocupen el lugar que les corresponde en un organigrama equilibrado de la Unión Europea. Si el crecimiento desmesurado del órgano de representación regional rompiese el equilibrio, la resultante sería mala para todos. Lo importante es la construcción de una Europa integrada en la que todas y cada una de las parte, ocupen el lugar adecuado». [Santiago Petschen Verdaguer, «Las regiones de la Unión Europea: aspiraciones y posibilidades», Actas del II Simposio de Historia Actual: Logroño, 26-28 de noviembre de 1998: 165.]. 
biernos subestatales en la construcción europea es aún una asignatura pendiente. La ausencia de referencias a las Regiones en el Libro Blanco relativo al futuro de Europa publicado en marzo de 2017 por la Comisión Europea, da prueba de ello.

Todo ello evidencia una visión hegemónica de los Estados como únicos interlocutores y sujetos legitimados para intervenir en el proceso de toma de decisiones de la UE. En este punto resulta obligado recordar la heterogeneidad de realidades que se engloban bajo el término «región», realidades que comprenden desde las regiones que son fruto de una mera descentralización administrativa a aquellas con competencias legislativas y/o que representan a realidades nacionales no estatales.

En todo caso, en un escenario global cada vez más marcado por el policentrismo y la interdependencia y caracterizado por una exigencia creciente de gobernanza multinivel, es fundamental el encaje de las regiones, y en especial de las que podríamos denominar Regiones Constitucionales - regiones con competencias legislativas y aquellas que representan a realidades nacionales sin Estado-, en la futura gobernanza de la Unión. Y no sólo con el objetivo de dotar de una mayor legitimidad al proceso de integración, sino también para alcanzar mayores cotas de eficiencia y de coherencia en el desarrollo de las políticas públicas comunes.

Cabría plantear propuestas que fortalecieran la dimensión política de la UE, entre las que podrían encontrarse las siguientes: la elección de la persona que ostente la Presidencia de la Comisión Europea por parte del Parlamento Europeo (Spitzenkandidaten) de entre los candidatos y las candidatas de los distintos grupos políticos presentados a las elecciones europeas; una reducción sustancial del número de Comisarios/as europeos/as obedeciendo su designación a parámetros de eficacia y no de nacionalidad; la implantación progresiva de listas únicas transnacionales europeas que vayan sustituyendo a las circunscripciones estatales y regionales en las elecciones al Parlamento Europeo; el establecimiento de medidas para garantizar una presencia equilibrada de mujeres y hombres en puestos y órganos de representación política; la paulatina eliminación de la unanimidad en el Consejo; la implantación de la codecisión del Parlamento Europeo en todas las materias (incluyendo la fiscalidad); la celebración de las elecciones al Parlamento europeo en un mismo día en toda la Unión Europea; la ampliación de la capacidad de iniciativa legislativa al Consejo y al Parlamento Europeo; el establecimiento de una cámara o, subsidiariamente, de una comisión específica para las y los europarlamentarios de la eurozona.

Y desde un enfoque de gobernanza multinivel cabría proponer la constitución de una convención sobre la gobernanza multinivel que retome los trabajos realizados en su día en el grupo de trabajo sobre sub- 
sidiariedad de la Convención europea, en especial el informe Lammassoure relativo a la figura de la Región Asociada, y proceder a la reforma del Comité Europeo de las Regiones de forma que se le otorgue la categoría de institución, se amplíen las materias sometidas a consulta, se dote de fuerza vinculante a sus dictámenes en determinadas materias y se aborde adecuadamente la heterogeneidad de su composición.

El fomento de la ciudadanía activa resulta clave para que el protagonismo político y decisorio de la UE sea compartido con los pueblos y naciones que integran Europa. Una Unión más democrática exige una ciudadanía formada en valores, con acceso a una formación y especialización de calidad. Igualmente requiere la promoción de la diversidad cultural y lingüística. Y por encima de todo, el desarrollo de una Europa social claramente anclada en el método comunitario superando la intergubernamentalidad.

\section{Una nueva gobernanza para Europa}

Los líderes políticos deben ser capaces de trasmitir a sus ciudadanos esperanzas renovadas. La legitimidad de Europa - basada en la obligación, consagrada en el vigente Tratado de Lisboa de la Unión Europea, orientada a promover «el bienestar de su población»- está en juego. Nuestro problema no revela solo una incapacidad para anticiparse a los problemas, sino que muestra además nuestra reticencia a actuar. Por todo ello, ponernos de acuerdo en definir esos intereses comunes es clave para iniciar el camino hacia un futuro mejor. Ha de ser, por encima de otros intereses partidistas, el primer, obligado y fundamental ámbito para el consenso político y social.

¿Necesita Europa una nueva Gobernanza? ¿Existe una Ciencia de la toma decisiones políticas que permitan sacar al proyecto europeo de su letargo? ¿Qué papel debe jugar la nueva Gobernanza y la política en la refundación de Europa? cabría afirmar sin exageración que estamos ante un proceso de transformación social que interpela a la política como lo hicieron, hace cuatrocientos años, aquellos cambios sociales que estuvieron en el origen de la invención de los modernos Estados nacionales. Son estos procesos los que están produciendo actualmente unas transformaciones insólitas en las formas institucionales, instrumentos y mecanismos de coordinación gracias a los cuales las sociedades actuales intentan resolver sus problemas colectivos y proveer los bienes públicos.

Podemos calificarlos de cambios irreversibles, que no obedecen a una moda pasajera, sino a cambios estructurales, como la globalización de la economía, la configuración de sociedades del conocimiento, la individuali- 
zación de los estilos de vida, la sociedad del conocimiento o la europeización de nuestras sociedades. En medio de estas turbulencias, no se trata de mejorar la eficacia de la política tradicional, ni siquiera de adaptarla a unas nuevas realidades, sino de entender cuál es la función que tenemos derecho a esperar de la política en un mundo diferente.

En el excelente trabajo colectivo surgido tras una reflexión pluridisciplinar en torno a la crisis europea, los investigadores Carlos Closa, Miguel Maduro y Daniel Innerarity subrayan una idea clave: existe entre la opinión pública de numerosos Estados miembros una profunda preocupación y dudas respecto del significado de la UE y su integración, provocando así una actitud escéptica que antes no existía. Los desafíos van desde el temor a la desintegración del euro hasta la posibilidad de generalizar la integración diferenciada pero, no nos cabía duda de que convergen en torno al debate sobre tres principios básicos: legitimidad, democracia y justicia.

De la crisis actual sólo saldremos con nuevos significados. Y para ello se requiere un salto conceptual que nos permita comprender y explicar las ventajas y los deberes de la interdependencia. Sólo una comprensión de las utilidades del proyecto europeo nos hará capaces de superar el «miedo demoscópico» (Habermas) que atenaza a nuestros dirigentes y explica la primacía del corto plazo en sus decisiones, así como la deriva populista de nuestras sociedades ${ }^{20}$. Es necesario entender hasta qué punto la UE constituye un instrumento para aliviar los efectos negativos de la globalización y recuperar a nivel europeo algunas de las capacidades perdidas en el plano

20 Sin ninguna duda, uno de los mayores enemigos de cualquier sociedad democrática es la demagogia. Desafortunadamente, lo que ocurre en la actualidad no es algo nuevo sino que, como bien explicó el filósofo José Ortega y Gasset en la citada conferencia de Múnich en 1953 (De Europa meditatio quaedam), los irresponsables personajes que son los demagogos tienen por única táctica el extremarlo todo para así poder «alcoholizar»/ «envenenar» a los ciudadanos y ciudadanas. Como muy bien indicó, y hoy en día ocurre a lo largo y ancho de todo el panorama político, convierten la conciencia de Nacionalidad en programa político, lo cual deriva en nacionalismo. Pues bien, cualquier -ismo es catastrófico; son - explicó - los dogales de seda con que pensadores y pueblos suelen estrangularse. [Ortega, Meditación..., 123-124.] Igualmente, es interesante traer a colación aquí otras palabras de este autor escritas en su obra «El hombre y la gente». En efecto, a este respecto señaló que los demagogos son empresarios de la alteración que han hecho morir a varias civilizaciones. Hostigan a las personas para que no reflexionen y procuran mantenerlos hacinados en muchedumbres para que no puedan reconstruir su persona donde únicamente se reconstruye, en la soledad. Esto es de gran interés para lo que más adelante se dirá acerca de que la Unión Europea actual y del futuro ha de defender un modelo social que ponga a las personas, a los ciudadanos y ciudadanas, en el centro de sus decisiones y de sus preocupaciones. [José Ortega y Gasset, Obras completas. Tomo IX_1933/1948. (Sabadell: Taurus, 2017), 281-440]. 
estatal. La UE tiene que ser capaz de mostrar que añade valor a la mera yuxtaposición de Estados nacionales.

Vivimos acontecimientos sin precedentes que han de concluir en la obligada reconfiguración del sistema financiero internacional y que pone en cuestión la ortodoxia económica liberal. Y creo, en primer lugar, que es el tiempo de la política, y en particular de la política europeo/Comunitaria.

La política exige reflexión, discusión, debate....y las innovaciones en otros ámbitos de la vida social y económica discurren a un ritmo vertiginoso. Ese desajuste entre las esferas económica y financiera (que trascurren a ritmo de alta velocidad) y la política no debe servir para «demonizar» la respuesta política. Al contrario: una sociedad sin debate político será siempre una sociedad menos libre y menos justa, y en este año 2019 todos los europeos afrontamos el reto democrático de las elecciones al Parlamento Europeo.

La complejidad inherente al proceso de toma decisiones en el seno de las instituciones Europeas requiere de un nuevo andamiaje institucional, representado por el imperfecto pero sin duda necesario Tratado de Lisboa. Ha de cobrar protagonismo el ritmo político, el liderazgo político, pero ha de ser una política que supere la mera improvisación inteligente del «ir tirando», una política que supere la simple agitación en superficie, esa falsa movilidad como señuelo para que en realidad no cambie nada, un pseudomovimiento que en realidad disfraza la ausencia de toma de decisiones.

Todo ello plantea la exigencia y el reto del liderazgo político, y permite reivindicar el momento de Europa y de sus instituciones: es el momento de reconquistar el futuro, alejado de una mera suma de expectativas individuales, desligadas de realizaciones colectivas. La solución a este largo y oscuro túnel no puede venir de la mano de soluciones de rescate ad hoc y unilaterales. La respuesta a esta cuestión debe comenzar por una evidencia: la impotencia de los Estados-Nación frente a las consecuencias de la globalización. Es la hora de apostar más por la UE, porque el diseño institucional y las herramientas de que disponen los Estados por sí solos devienen insuficientes para hacer frente a las dinámicas desencadenadas por los mercados globales ${ }^{21}$.

La complejidad y la magnitud de la crisis vivida puso de manifiesto estas carencias y realzó la importancia de la dimensión Europea, que deriva en un factor clave al resultar más apropiada y eficaz que la suma

${ }^{21}$ Sobre el concepto de Gobernanza económica europea, la débil arquitectura institucional y el nuevo impulso de la gobernanza económica europea, vid. Iñarritu Ibarreche, Beatriz, La gobernanza... pp.21-98. 
atomizada de ámbitos estatales tradicionales. El desafío que supone para nuestra clase política y nuestra sociedad la dimensión de esta crisis aporta argumentos adicionales para apostar por Europa, una Europa abierta, no cerrada sobre sí misma ${ }^{22}$.

Cuando hablamos de innovación estamos habituados a pensar en ciencias experimentales, economía y tecnologías, pero no en ciencias humanas, en las sociedades y, mucho menos, en sus gobiernos. Uno podría quejarse por esta restricción del concepto de innovación, pero la verdad es que hay alguna razón que explica el hecho de que casi nadie asocie la política con alguna novedad. Es llamativo que en el mismo mundo convivan la innovación en los ámbitos financieros, tecnológicos, científicos y culturales con una política inercial y marginalizada.

El repliegue de la política frente al vigor de la economía o al pluralismo del ámbito cultural es un dato que merece ser tomado como punto de partida de cualquier reflexión acerca de la función de la política en el momento actual. Es una valoración casi unánimemente compartida que la capacidad configuradora de la política retrocede de manera preocupante en relación con sus propias aspiraciones y con la función pública que se le asigna. No se trata de defectos de las personas o incompetencias singulares sino de un déficit sistémico de la política, de escasa inteligencia colectiva por comparación con el vitalismo de otros ámbitos sociales. Esa escasa capacidad

22 Por ello resultan prescindibles todos aquellos proyectos de la Unión Europea que se basen en la preponderancia de los Estados en detrimento de una cada vez mayor integración. Así, y como bien exponen David Ramiro Troitiño, Abel Polese y Stefano Braghiroli, dichos modelos siguen la estela del modelo de Europa que defendió el general francés Charles de Gaulle. Para éste no existía el concepto de soberanía compartida (de hecho, estaba en contra del concepto de pueblo europeo por entender que no existía) y, por ende, los Estados eran independientes con un absoluto control de su soberanía nacional. También defendió una alta posibilidad de veto por parte de los Estados a las políticas comunes europeas (lo cual se traducía en una eliminación del carácter supranacional del proyecto Europeo); una política exterior independiente; la promoción de la energía nuclear; y un uso egoísta de los recursos europeos en beneficio propio. En otras palabras, y tal y como señalan los autores, este tipo de modelos están cimentados en el más rancio nacionalismo extremo, ortodoxo y conservador y, por tanto, contrario al principio de solidaridad que ha de informar el proyecto europeo. Así, constituye el paradigma de la viejas políticas que conducen al fracaso que es toda guerra. [David Ramiro Troitiño, Abel Polese y Stefano Braghiroli, «De Gaulle y Europa. Nacionalismo francés frente a integración en la construcción europea», Revista de Occidente, n. 443 (2018): 88; 90; 91; 93: 96; 98; y 100.]. En definitiva, se puede decir que tanto Charles de Gaulle como su modelo de Europa confirman la aseveración hecha por el filósofo José Ortega y Gasset en su discurso dado en Berlín en 1949 (De Europa meditatio quaedam) consistente en que «No sabíamos que jamás un general hubiera compuesto ningún purana filosófico que mereciese la pena. Creíamos que los generales carecen en general de ideas generales». [Ortega, Meditación..., 122]. 
de innovación de la política tiene mucho que ver con el hecho de que haya desatendido «la confrontación con las transformaciones que han vaciado progresivamente desde el interior sus categorías y sus conceptos» (Giorgio Agamben).

Vivimos efectivamente en una sociedad descompensada: entre la euforia tecno-científica y el analfabetismo de valores cívicos, entre la innovación tecnológica y la redundancia social, entre cultura crítica en el espacio de la ciencia o en el mundo económico y un espacio político y social que apenas se renueva. Hace tiempo que las innovaciones no proceden de instancias políticas sino de la inventiva que se agudiza en otros ámbitos de la sociedad. No se concibe, sino que se repara, desde una crónica incapacidad para comprender los cambios sociales, anticipar los escenarios futuros y formular un proyecto para conseguir un orden social inteligente e inteligible.

La política es una acción cuyas consecuencias tienen mayor alcance que sus previsiones. Este contraste, que vale para casi todas las acciones humanas, es especialmente agudo en el caso de aquellas que como la política se llevan a cabo en medio de una incertidumbre extrema. Las nuevas situaciones recuerdan a la política que ha de plantearse la pregunta de si está ante problemas que simplemente puede solucionar o si se trata de transformaciones históricas que exigen una nueva manera de pensar.

El largo recorrido temporal de esta crisis nos mostró que con el recurso único a la política monetaria, por muy sólida y coordinada que ésta sea, no será posible salir de la misma o atemperar sus efectos. Ésta debe complementarse con medidas de pura política financiera, auténtico reto para Europa en estos momentos tan catárticos.

El Pacto de Estabilidad debe venir acompañado, en la zona Euro, de un pacto de coordinación de las respectivas políticas económicas ${ }^{23}$. Y no debe olvidarse que el Euro ha supuesto y está suponiendo una coraza protectora frente a economías nacionales que, caso de haber mantenido en circulación sus débiles monedas nacionales habrían sucumbido a la crisis de forma estruendosa. Una devaluación, sumada a todos los negativos indicadores antes señalados, habría supuesto un daño irreversible y difícilmente reparable para las maltrechas economías domésticas europeas.

Ante la impotencia de los Estados-Nación frente a las consecuencias de la globalización, es hora de apostar más por la UE. La complejidad y la magnitud de la crisis pone de manifiesto estas carencias y realza la impor-

${ }^{23}$ Sobre el particular, vid. Laura Huici Sancho, « Los instrumentos de control democrático y de rendición de cuentas en el gobierno de la Unión Económica y Monetaria», RVAP, enero-abril 2018, pp.23-49. 
tancia de la dimensión Europea, al resultar más apropiada y eficaz que la suma atomizada de ámbitos estatales tradicionales ${ }^{24}$.

De forma casi silente va acercándose la fecha de una nueva cita con las urnas, la del Parlamento Europeo. La apatía, la desafección ciudadana y el escepticismo social marcan esta nueva convocatoria electoral. ¿Cómo activar la conciencia ciudadana ante la sensación de una Europa anclada en lo intergubernamental, donde mandan tecnócratas no elegidos por nosotros y ejecutan sus decisiones dirigentes estatales solo preocupados de su perpetuación en el poder nacional?; ¿Cómo explicar al ciudadano de a pie para qué sirve el Parlamento Europeo, convertido en una especie de «pepito grillo» de la conciencia europeísta, pero sin apenas capacidad real de influencia en la política Comunitaria?25.

${ }^{24}$ Tal y como indican Antonio Moreno Juste y José Luis Neila Hernández en su trabajo, «un notable incremento de las actividades económicas transnacionales [...] acabaron poniendo al Estado-nación contra las cuerdas. Si bien, el Estado-nación ha continuado siendo la unidad política de referencia, ha perdido el control de la economía y carece de los instrumentos para poder mantener objetivos claves del modelo social europeo como el pleno empleo y la mejora continuada de los niveles de vida. La consecuencia no ha sido otra que un progresivo aumento del malestar político, paralelo a la pérdida de legitimidad del Estado y resultado de la creciente brecha entre lo que los políticos dicen que son capaces de hacer y lo que en realidad puedan hacer, [...] y su corolario, una crisis política estructural [...] cuyo rasgo diferenciador en la actualidad es una caída brutal de las expectativas de futuro de la ciudadanía europea en correlación directa con el desmantelamiento del Estado del Bienestar». [Moreno Juste y Neila Hernández, «Europa tres décadas después de la caída del Muro», 53].

${ }^{25}$ Una buena radiografía de la realidad europea actual nos la ofrece el filósofo Jürgen Habermas en su libro «En la espiral de la tecnocracia». En efecto, como bien nos explica Bernat Gispert, en esta obra insiste el filósofo en la articulación europea de una estructura democrática multinacional o transnacional y, además, autónoma para hacer frente a una economía globalizada. De este modo, observa Habermas que los marcos políticos establecidos por los Estados-nación han caducado definitivamente. Asimismo, dice Bernat Gispert que «La pérdida de autonomía de los diferentes ejecutivos de los países miembros de la UE ante organismos internacionales - europeos y globales - representa un límite ineludible para la intervención democrática de la ciudadanía en las tomas de decisión política. Dicho límite es, pues, un obstáculo para la democracia. Ante tal situación, Habermas interpreta que el nacionalismo de los distintos países de la UE [...] en ningún caso representa ya una estrategia efectiva que retorne capacidad operativa a los gobiernos locales. Capacidad, cabe decir, imprescindible para la ejecución efectiva de la libertad política. La situación, así descrita, es harto alarmante para este filósofo [...], según el cual la deriva antidemocrática de la política europea urge ser atendida más allá del lamento inoperante de un euroescepticismo creciente. En contraposición, dice el autor, se requiere un realismo maduro que asuma que frente a políticas y economías globalizadas [...], no puede ya escaparse con un salto al pasado que reivindique el Estado-nación como sujeto político adecuado». A más abundamiento, en el propio libro se hace referencia al «reto de dar un nuevo paso cualitativo hacia una Europa nuclear unida políticamente». Y en este sentido nos expone Bernat Gispert que Habermas explica que «La situación en la que unos países altamente endeudados son dirigi- 
Hasta el momento, únicamente el Parlamento Europeo se elige por sufragio directo. Pero quien propone el Ejecutivo de la UE (al presidente de la Comisión Europea y a sus comisarios) es el Consejo Europeo, y el Parlamento lo somete posteriormente a votación. Y eso se debe a que esos cargos se ocupan sin tener en cuenta el resultado electoral. Por todo ello, los ciudadanos no valoran las elecciones al Parlamento Europeo. Para definir los verdaderos intereses europeos es necesario que se produzca un debate serio, honesto y paneuropeo, en lugar de uno que no sea más que la suma de los debates nacionales. La discusión debe ser pública e involucrar a los ciudadanos europeos, que llegue más allá del reducido círculo de líderes políticos inscritos en el marco del Consejo Europeo. Este periodo previo a las elecciones al Parlamento Europeo de 2019 podría ser una oportunidad para entablar un verdadero debate público sobre su futuro. Pero lo intergubernamental, lo estatal sigue primando sobre lo europeo, tristemente.

Por si fuera poco, a todo ello se suma la metodología electoral europea, que remite a la normativa interna de cada Estado, a efectos de aplicar su propio sistema electoral. En nuestro caso el Estado español optó desde su incorporación a la Unión Europea por la circunscripción electoral estatal y única, frente a modelos descentralizados electoralmente ante la cita con las urnas europeas, como Francia, Irlanda, Italia, Polonia o Bélgica.

Por un lado, esta opción juega en contra de los intereses de los partidos que desean formular sus propuestas en clave europea pero en proyección concreta sobre su ámbito territorial de actuación política; además, repercute

dos externamente - en sus decisiones presupuestarias y fiscales- por actores politicos no electos es la que se alude cuando se habla de tecnocracia. Habermas denuncia, por consiguiente, que tales agentes ejecutivos [...] son, de facto, absolutamente impermeables al voto de la ciudadanía. Más allá del organigrama institucional de la UE, el déficit democrático de la ciudadanía europea sólo puede superarse [...] ampliando las cuotas de participación directa del electorado de los países miembros en los organismos políticos comunitarios; hecho que, sin duda, va mucho más allá del acostumbrado marco nacional de los distintos países de la Unión. Sin embargo, "esta ampliación de la perspectiva del nosotros desde el ciudadano del Estado a, ciudadano europeo, constitutiva de la comunidad europea, aparece en los juegos de simulación de la Comisión en el vergonzoso lugar de una especie de apéndice". Las autoridades supranacionales deben hallar fuentes de legitimación democrática para frenar el ejercicio tecnocrático habitual en ellas pues, de no ser así, se seguirá rodando en esa "espiral de la tecnocracia" que se opone al ejercicio de la democracia deslegitimando, con ello, toda decisión política que de ella dependa». Por ello, en el propio libro Habermas solicita a la República Federal Alemana que asuma la responsabilidad de implementar inmediatamente una democracia transnacional para acabar con la tecnocracia. Finaliza el filósofo recordando que «cuanto más aumenta la complejidad de la sociedad y los problemas por regular políticamente, menos parece ser posible salvaguardar la ambiciosa idea de la democracia, según la cual los destinatarios del derecho deberían ser al mismo tiempo sus autores». [Bernat Gispert, «Último canto a la democracia europea», Revista de Occidente, n. ${ }^{\circ} 444$ (2018): 135; 136; 138; y 139]. 
negativamente sobre el nivel de participación, porque aleja realmente al votante de su realidad más próxima y de la incidencia del debate electoral sobre su realidad cotidiana, y favorece el bipartidismo estatal: en realidad responde a un cálculo electoralista interesado y promocionado desde determinadas opciones políticas, en particular desde los grandes partidos políticos con implantación estatal ${ }^{26}$.

Son tres las posibles alternativas que a futuro puede presentar la necesaria y deseable reforma del proceso electoral europeo: La opción dominante, a la que lamentablemente se acoge el Estado español, consiste en seguir la inercia política representada por el mantenimiento inalterado de las circunscripciones estatales: es la tesis estatalista e intergubernamental en estado puro, y sin duda representa la alternativa preferida por los Gobiernos de los Estados, celosos y centrados en conservar su poder soberano dentro de la Unión Europea. Éstos se aseguran así una proyección a escala europea del equilibrio de fuerzas dominante en el interior de sus respectivos Estados, y se «estatalizan» $\mathrm{o}$ «nacionalizan» las elecciones europeas.

Una segunda opción defendería abrir el sistema electoral europeo a toda una serie de circunscripciones subestatales, mediante un sistema de reparto de escaños proporcional a la población de cada circunscripción. Esta modalidad favorecería una verdadera pluralidad y riqueza política en el Parlamento, reflejo a su vez de la atomizada oferta política existente a nivel europeo, y es la opción defendida por la propia Comisión de Asuntos Constitucionales del Parlamento Europeo. La propuesta, muy relevante para Euskadi, preveía incluso la posibilidad de establecer circunscripciones especiales «para satisfacer las necesidades de las minorías lingüísticas». Pero una vez más esta propuesta ha quedado hibernada para mejor época.

El tercer escenario de cambio nos acercaría hacia el establecimiento de un modelo transnacional de elecciones europeas en el que el conjunto de la Unión se configuraría como una circunscripción europea, combinándose con la existencia de otras circunscripciones estatales o subestatales. Esta circunscripción abarcaría el conjunto del territorio de la Unión, en clave cuasifederal: un sueño europeísta tristemente lejos de convertirse en realidad, pero al que debemos aspirar.

${ }^{26}$ En tal sentido, vid., Manuel Cruz. «La política que viene y la política que se necesita». En ¿Dónde vas, Europa?, editado por Miquel Seguró y Daniel Innerarity, pp. 87-101, al aclarar que hay que poner remedio a la escasa porosidad de los partidos, tanto en lo que respecta a las personas como respecto a las ideas. De la misma manera que hay que impulsar también un debate político de calidad. Ello implica, en primer lugar, alejarse de la sistemática adulación a la ciudadanía, cuyo reverso suele ser la (auto) devaluación de la política. Frente a ello, urge recuperar su prestigio institucional, huyendo de las demagogias de matriz antipolítica. 
La petición o propuesta de más Europa no ha de ser hueca, sino que debe traducirse en generar un clima de confianza recíproca interestatal que culmine en una mayor atribución competencial a las instituciones europeas, necesaria para liderar una nueva y auténtica política financiera Comunitaria, como base para evitar caer en el futuro en los mismos errores del pasado.

La crisis financiera no ha sido solo debida a una defectuosa (o inexistente) regulación o a la falta de verdadera supervisión sobre la voracidad lucrativa de los operadores. Ha sido también el resultado de una crisis de valores. Y junto al necesario rearme moral y ético de los mercados es preciso articular un andamiaje, un mecanismo normativo sólido, estructural y no meramente coyuntural ${ }^{27}$.

Esta dura crisis ha tenido y tiene su más dramático exponente en la vertiente social que muestra el empobrecimiento y las dificultades vitales de personas y familias que no alcanzan a vislumbrar un futuro con empleo y modos de vida dignos. Por ello, numerosos referentes políticos y mediáticos sitúan en el centro del debate la cuestión relativa al alcance y extensión de la denominada Europa Social. ¿Tiene realmente la Unión Europea una auténtica política social? ¿Cómo gobernar en clave Comunitaria la imparable mundialización/globalización económica?.

En la actualidad no existe un auténtico modelo social europeo sino varios modelos nacionales en el marco de la UE, con criterios o características heterogéneas. ¿Por qué no armonizarlos sobre la base de dos principios básicos, los de solidaridad y justicia social? Tenemos ya una maltrecha unión económica y monetaria; ¿para cuándo una Europa social que permita vertebrar la sociedad europea?

Las bases sobre las que asentar los elementos troncales del modelo social europeo han de ser la creación de empleo estable, la garantía de un sistema público de pensiones viable, la atención a los desempleados mediante apoyo directo y medidas de formación, la integración de la inmigración, articulando sistemas de protección a los trabajadores, un conjunto básico de normas tuitivas, protectoras del Derecho Laboral, sistemas de seguridad social y estructuras de concertación social armonizadas. Debemos estar unidos dentro de la diversidad para salir así reforzados por el sentimiento de defensa de un modelo social europeo que ponga a las personas, a los ciuda-

27 En tal sentido, vid., Miquel Seguró. «Punto de partida». En ¿Dónde vas, Europa?... p.17, al subrayar que desde 2000 existe una Carta de los Derechos Fundamentales de la Unión Europea en la que se habla de principios como la dignidad, la solidaridad o la justicia. Pero la noción de ciudadanía que de ahí emana parece darse de bruces con la realidad de los hechos, con la implacable agenda de lucha de intereses financieros de los gobiernos de los Estados Miembros, religados, a su vez, a los dictados de las empresas privadas que condicionan sus agendas. 
danos, y no a los mercados, en el centro de sus decisiones y de sus preocupaciones como proyecto político.

Crear esa Europa Social del futuro pasa por la desburocratización y democratización de la misma y por lograr una mayor eficiencia de los recursos, ya que el incremento del gasto social sin más no es suficiente. Democracia y Estado social se interaccionan permanentemente, y dependen uno del otro.

Las críticas vertidas hacia el vigente Tratado Europeo ponen el acento en que consolida una especie de neoliberalismo comunitarizado. La política social queda excesivamente ligada a los intereses dominantes de las grandes corporaciones y es preciso coordinar el factor económico y el social para lograr así redefinir el modelo social. Esta añorada Europa social ha sido tradicionalmente el pariente pobre de la construcción europea.

La Europa Social camina por detrás de la Europa del mercado. No existe una competencia directa a favor de la UE en materia de protección social. Como parte integrante del Derecho europeo, y en el elenco de los Derechos Fundamentales de la Unión, cabe destacar los relativos a la libertad profesional y derecho a trabajar, libertad de empresa, el Derecho a la información y consulta de los trabajadores en la empresa, negociación y acción colectiva, acceso a los servicios de colocación, protección en caso de despido injustificado, derecho a trabajar en condiciones justas y equitativas, prohibición del trabajo infantil y protección de los jóvenes en el trabajo, protección de la vida familiar y la vida profesional, derecho de acceso a las prestaciones de seguridad social y a los servicios sociales que garantizan una protección en casos como la maternidad, la enfermedad, los accidentes laborales, la dependencia o la vejez, así como la pérdida de empleo y la protección de la salud.

El escenario normativo-institucional idóneo sería aquel que lograra coordinar de manera eficaz y democrática las políticas económicas, las presupuestarias, las sociales y las de empleo de los Estados miembros, situando la moneda única como instrumento al servicio de una auténtica estrategia de desarrollo sostenible y profundización del modelo social europeo. El logro de tal objetivo requiere que la política social y la política de empleo se sitúen en la Unión al mismo nivel que la política económica, es decir, como de interés común, siendo gestionadas como un conjunto integrado.

¿Qué nos falta? impulso y liderazgo político para materializar una Europa que ilusione a sus ciudadanos. Ante la crisis y el desconcierto institucional cabe reclamar sin duda, más Europa, pero con una mayor profundización en los valores del modelo europeo de sociedad. O nos integramos más o nos desintegramos como proyecto político europeo. El reto merece la pena. 
La dimensión conocida como la «Europa Social» es clave para retomar la senda de adhesión de la ciudadanía al proyecto europeo, es cierto que el propio Tratado de Lisboa insta a trabajar en pro del desarrollo sostenible basado en una economía social de mercado tendente al pleno empleo y al progreso social. Además aboga por garantizar una protección social adecuada, la lucha contra la exclusión social y la exigencia de un nivel elevado de educación y formación. Como corolario a todo ese elenco importante de objetivos, el Tratado de Lisboa señala que la Unión debe combatir la discriminación y fomentar la justicia, la igualdad entre mujeres y hombres y la solidaridad entre las generaciones. Son, todos ellos, objetivos loables y bienintencionados, pero la UE sigue adoleciendo de medidas directas destinadas a la ciudadanía europea.

Dentro del debate global sobre el futuro de Europa y con el referente temporal del año 2025 esta dimensión social, centrada en las transformaciones futuras de las sociedades europeas, en la mejora de los sistemas educativos y la necesidad de formación a lo largo de la vida para afrontar los retos sociales que se plantean así como en la preparación para escenarios laborales dinámicos ha adquirido especial protagonismo.

Las instituciones europeas proclamaron en noviembre de 2017 el Pilar Europeo de Derechos Sociales, que establece veinte principios y todo un elenco de derechos clave para fortalecer la igualdad de oportunidades y el acceso al mercado de trabajo, unas condiciones laborales justas y la protección e inclusión social para toda la ciudadanía europea. El objetivo último es garantizar a la ciudadanía el ejercicio efectivo de sus derechos a través de la adaptación del modelo social europeo frente a los mencionados desafíos.

¿Cómo lograr que tal listado de objetivos plasmados en este Pilar europeo de los derechos sociales no quede limitado a una declaración de principios sin virtualidad práctica? para testar su efectividad y ganar en credibilidad social su implantación debiera conducir a la consecución de un mercado laboral justo en toda la UE al tiempo que contribuye activamente a la viabilidad de los sistemas de bienestar dando adecuada respuesta a retos como el envejecimiento de la población. Y la clave, una vez más, radica en profundizar en las bases de la integración europea, algo que permitiría, sin llegar a una muy compleja armonización entre todos los sistemas vigentes en la UE, lograr un mínimo común denominador, una regulación básica a nivel europeo de las condiciones de trabajo, salario mínimo y estándares sociales básicos, incluida una renta de garantía de ingresos, que aseguren una vida digna a las ciudadanas y ciudadanos europeos al tiempo que garantiza el acceso igualitario de hombres y mujeres a los derechos sociales. Esta regulación deberá inspirarse en el principio de subsidiariedad y tener en cuenta la diferencias en el coste de vida entre los Estados miembros. 
Y en coherencia con los principios de subsidiariedad y proporcionalidad cabe proponer la directa y activa participación de los gobiernos regionales en la gestión de instrumentos como el Fondo Social Europeo y la garantía juvenil ya que es a nivel subestatal donde se aplican las políticas activas de empleo, incluyendo la innovación social y las políticas de igualdad. Este renovado Pilar europeo de los derechos sociales ha de incorporar a todas las administraciones, especialmente a las más cercanas a la ciudadanía, al esfuerzo por avanzar en el ámbito social y del empleo.

Se propone promover, en coordinación con la UE, el trabajo que a nivel regional se realiza en ámbitos como: la activación laboral, la generación de oportunidades, el apoyo a la economía social, el espíritu emprendedor y la economía digital, la consecución de un mercado de trabajo inclusivo que ofrezca oportunidades equitativas a mujeres y hombres y a todos los colectivos que lo conforman, así como un empleo de mayor calidad, o el desarrollo servicios de empleo eficientes que propongan itinerarios personalizados de ingreso en la vida laboral.

Desde las instituciones europeas debe nacer el impulso que posibilite la elaboración de una hoja de ruta para el desarrollo de este pilar, asociando la consecución de un verdadero mercado interior a la implantación de esquemas que garanticen unos ingresos mínimos adecuados y de unos estándares de salarios mínimos y condiciones de trabajo que erradiquen el dumping social. Este paquete de medidas, ligado a políticas de crecimiento sostenible, hará posible el progreso social y la sostenibilidad de las cuentas públicas.

\section{Conclusiones}

Los ciudadanos europeos nos debatimos entre la desafección y el malestar ante la forma de comportarse y de reaccionar frente a la crisis desde las instituciones europeas. No estamos en contra del proyecto europeo, sino de su actual rumbo. Es preciso reconstituir políticamente Europa. Hay que apostar por un liderazgo inequívocamente fuerte para reorientar bien la empresa común que representa Europa.

El punto débil de la UE, es decir, dar preferencia al mercado con respecto a la política, no sólo la vuelve impotente ante la crisis, sino que sobre todo le impide pensar en el futuro. Hoy no existe ninguna visión que impulse el futuro de Europa. La Unión tan sólo reacciona, y además con indolencia, ante los problemas coyunturales, inmediatos, absteniéndose de dar un paso adelante.

Hoy asistimos a la tendencia contraria: el paso atrás hacia la desintegración de la Unión entre el club de los países más fuertes y el de los más débiles, entre el centro y la periferia. La clase política dirigente afirma que 
quiere «calmar»a los mercados, pero de forma que los mecanismos sigan intactos y que después de la crisis, esos sacralizados mercados ocupen de nuevo el lugar de la política y de la integración política.

Ahí radica el mayor problema en nuestras sociedades europeas: los dirigentes políticos gobiernan cada vez menos, dejando un gran vacío en el lugar del ejercicio del poder a la antigua usanza. Vivimos en una democracia dispersa e individualizada donde el «sálvese quien pueda» triunfa, en la que a los dirigentes les cuesta determinar con claridad los objetivos de una comunidad ciudadana. Y crece el sentimiento de alejamiento entre los dirigentes y los ciudadanos, y el poder y la política en general escapan de las manos de los líderes políticos, sin que llegue a los ciudadanos.

Nuestra Unión Europea es una expresión flagrante de estas tendencias. Con el incremento dramático del paro, sobre todo entre los jóvenes, la Unión Europea ya no es la garantía de una vida decente y estable. El Estado del bienestar europeo, uno de los pilares tradicionales de la democracia, sufre un desmantelamiento progresivo, a veces inmediato. Las crecientes desigualdades avivan la indignación ${ }^{28}$. El miedo a la pobreza y a la degradación social se extiende incluso a las sociedades relativamente inmunes a la crisis. Carecemos de ideas sobre cómo salir indemnes. En esta situación, la mejor opción es volver a los orígenes, en este caso, a los de la Unión. La Europa unida era desde el inicio el proyecto político de la unificación del continente. Un proyecto para construir una federación de naciones en torno a un proyecto de futuro compartido.

Quizá los Estados son en ocasiones demasiado grandes para problemas pequeños, pero hoy, como lo demuestra la crisis griega y la de los restantes países del Sur de Europa, resultan demasiado pequeños para los grandes problemas. En medio de esta globalización es imprescindible hacer un ejercicio de realismo. Sólo queda responder de la única manera posible: innovación, internacionalización y conocimiento.

Esta crisis, la más grave de la historia reciente, ha derribado muchos conceptos poniendo en cuestión principios que creíamos asentados en nuestras sociedades y resucitando dilemas de alcance histórico. Y una víctima de la crisis será el actual Estado-bienestar, cuyos límites están asomando

${ }^{28}$ En este sentido, tal y como subrayan Antonio Moreno Juste y José Luis Neila Hernández, «la crisis trajo también un crecimiento de las desigualdades sociales a una escala desconocida desde la finalización de la Segunda Guerra Mundial. Tony Judt, aseguraba que la desigualdad corrompe las sociedades desde dentro y no le falta razón, a tenor de lo observado en la eurozona durante los últimos años. Ese malestar de fondo, unido a la crisis actual, ha terminado por marcar nítidamente la divisoria entre vencedores y perdedores del proceso de integración». [Moreno Juste y Neila Hernández, «Europa tres décadas después de la caída del Muro», 50]. 
claramente en estos escenarios de restricción fiscal, que exige inevitablemente un ajuste a las nuevas circunstancias económicas y financieras porque sólo su racionalización permitirá su supervivencia a largo plazo.

Es la hora de apostar más por la UE, porque el diseño institucional y las herramientas de que disponen los Estados devienen por sí solos insuficientes para hacer frente a las dinámicas desencadenadas por los mercados globales.

\section{Bibliografía}

Bengoetxea, Joxerramon. «Informe sobre Derechos Fundamentales y Ciudadanía europea en el Tratado constitucional». En La Constitución Europea. Una visión desde Euskadi, 17-23. Eurobask, 2005

Boronska Hryniewiecka, Karolina. «Multi-level governance and the role of the regions in the European Union: conceptual challenges and practical applications». Cuadernos europeos de Deusto n. ${ }^{\circ} 45$ (2011): 177-207.

Calonge Velázquez, Antonio. «El comité de las regiones en el futuro de Europa». Revista de estudios de la administración local y autonómica, n. ${ }^{\circ}$ 300-301 (2006): 227-254.

Calonge Velázquez, Antonio. «Europa. La última oportunidad: dos visiones sobre el futuro de la Unión Europea. Una recensión a propósito de los libros de Martin Schulz, "Europa: La última oportunidad" y de Giscard d'Estaing, "Europa. La última oportunidad"». Revista de derecho de la Unión Europea, n. ${ }^{\circ} 32$ (2017): $37-50$.

Cruz, Manuel, «La política que viene y la política que se necesita». En ¿Dónde, vas Europa?, editado por Miquel Seguró y Daniel Innerarity, 87-101. Barcelona, Herder Editorial, 2017.

De Castro Ruano, José Luis. «El comité de las Regiones en su vigésimo aniversario: hacia una redefinición de su papel político e institucional en busca de su lugar en el mundo comunitario». Revista de Derecho Comunitario Europeo, n. ${ }^{\circ} 18$ (2014): 917-941.

Delgado Rojas, Jesús Ignacio. «Recensión La Constitución de Europa, Jürgen Habermas, (2012) Trotta, Madrid, 128 pp.». Eunomía: Revista en Cultura de la Legalidad, n. $^{\circ} 5$ (2013): 328-335.

Domínguez Nacimiento, David. «Las regiones como actores en la Gobernanza Multinivel. Reflexiones sobre la legitimidad democrática». Encrucijadas: Revista Crítica de Ciencias Sociales, n. 3 (2012): 86-97.

Frosina, Laura. «Regiones y Unión Europea tras el tratado de Lisboa. El comité de las regiones, los parlamentos regionales y el desafío de la "multilevel governance"». Revista de Derecho constitucional europeo, n. ${ }^{\circ} 22$ (2014): 175212.

Gamper, Daniel. «Europa: entre la realidad negativa y la aspiración moral». En ¿Dónde, vas Europa?, editado por Miquel Seguró y Daniel Innerarity, 101-113. Barcelona, Herder Editorial, 2017 
Gispert, Bernat. «Último canto a la democracia europea». Revista de Occidente, n. 444 (2018): 135-140.

Innerarity, Daniel. La democracia en Europa, Barcelona: Galaxia Gutenberg, 2017.

Iñarritu Ibarreche, Beatriz. La Gobernanza Económica de la Unión Europea, Bilbao: Universidad de Deusto, 2018.

Mangas Martín, Araceli. «Postbrexit. Entre la Unión Europea necesaria y la posible». Revista de Occidente, n. ${ }^{\circ} 440$ (2018): 41-61.

Moreno Juste, Antonio y José Luis Neila Hernández. «Europa tres décadas después de la caída del Muro». Revista de Occidente, n. ${ }^{\circ} 418$ (2016): 36-57.

Menéndez, Agustín José, «La Unión Europea entre el constitucionalismo democrático y la gobernanza». Revista de estudios políticos, n. 149 (2010): 47-85.

Ortega y Gasset, José. Meditación de Europa y otros ensayos. Madrid: Alianza Editorial, 2015.

Ortega y Gasset, José. Obras completas. Tomo I_1902/1915. Sabadell: Taurus, 2017.

Ortega y Gasset, José. Obras completas. Tomo IV_1926-1931. Sabadell: Taurus, 2017.

Ortega y Gasset, José. Obras completas. Tomo IX_1933/1948. Sabadell: Taurus, 2017.

Nagel, Klaus-Jürgen. «Entre la "independencia en Europa", una "Europa con cien banderas" y una "Europa de" o "con las regiones"». Hermes: pentsamendu eta historia aldizkaria = revista de pensamiento e historia, n. ${ }^{\circ} 37$ (2011): 4-22.

Petschen Verdaguer, Santiago. «Una Europa de Estados, de Pueblos y de Regiones». Política y sociedad, n. 28 (1998): 63-70.

Petschen Verdaguer, Santiago. «Las regiones de la Unión Europea: aspiraciones y posibilidades». Actas del II Simposio de Historia Actual: Logroño, 26-28 de noviembre de 1998: 161-177.

Popartan, Lucía Alexandra e Israel Solorio. «Las regiones en la Unión Europea. Procesos y paradigmas». Revista CIDOB d'afers internacionals, n. ${ }^{\circ} 99$ (2012): 9-23.

Ramiro Troitiño, David; Abel Polese y Stefano Braghiroli. «De Gaulle y Europa. Nacionalismo frente a integración en la construcción europea». Revista de Occidente, n. ${ }^{\circ} 443$ (2018): 87-101.

Ramiro Troitiño, David y María de la Paz Pando Ballesteros. «El modelo de integración europea de Churchill». Revista de Occidente, n. ${ }^{\circ} 434$ (2017): 57-71.

Ripoll Navarro, Rafael. «La Europa de las regiones: propuestas de gobernanza». Revista valenciana d'estudis autonómics, n. ${ }^{\circ} 55$ (2010): 184-201.

Sanz Caballero, Susana. «Algunos signos de déficit democrático en el Tratado Constitucional Europeo y en su Carta de Derechos Fundamentales», en La Constitucionalización del proceso de integración Europea, 273-289. Escuela Diplomática, Madrid, 2005

Seguró, Miquel. «Punto de partida». En ¿Dónde, vas Europa?, editado por Miquel Seguró y Daniel Innerarity, 15-23. Barcelona:Herder Editorial, 2017 


\section{Sobre el autor}

Juan José Álvarez es Doctor en Derecho, en el área de Derecho Internacional Privado, por la UPV/EHU; obtuvo el premio extraordinario de Doctorado, junto al Premio Extraordinario de Licenciatura y examen de Grado, con la Calificación de Sobresaliente/ Matrícula de honor. Recibió el Premio Eusko-ikaskuntza-Laboral Kutxa de Humanidades, Cultura, Artes y Ciencias Sociales del año 2015. Es Catedrático de Derecho Internacional Privado de la UPV/EHU y profesor visitante en numerosas Universidades y centros de investigación nacionales y europeos. Ejerce igualmente como Consejero-Abogado de la firma de abogados CUATRECASAS y es cofundador y Secretario de GLOBERNANCE (Instituto para la Gobernanza Democrática). Fue Secretario General del Consejo Vasco del Movimiento Europeo (EUROBASK/CVME) (Mayo de 2003-2012) y designado como experto por la COMISIÓN EUROPEA (Dirección General de Justicia, Libertad y Seguridad), con fecha 17 de diciembre de 2007, para las áreas de Justicia Civil, fronteras, protección de datos personales y ámbitos de seguridad. Sus líneas de investigación se centran en el Derecho Marítimo, Derecho del comercio internacional y DDHH, Derecho europeo y ámbitos vinculados a los conflictos internos. Entre sus últimas investigaciones cabe citar Las Lecciones Jurídicas del Caso Prestige». Hacia un nuevo Derecho de daños marítimo: tendencias actuales (ARANZADI THOMSON REUTERS, 2012), Human Rights in Business. Removal of Barriers to acces to Justice in the European Union TAYLOR-FRANCIS, 2017), «Brexit y Gibraltar: la perspectiva de las personas jurídicas. Incidencia sobre la libertad de establecimiento y prestación de servicios», El Brexit y Gibraltar. Un reto con oportunidades conjuntas, Madrid, (ESCUELA DIPLOMÁTICA, 2017), «Crisis Matrimoniales y Conflictos de leyes internos», Crisis Matrimoniales Internacionales y sus efectos. Derecho Español y de la Unión Europea, TIRANT LO BLANCH, 2018). Es coordinador del observatorio jurídico transfronterizo hispanofrancés y director de la Cátedra Universidad-Empresa de CONFEBASK.

\section{About the Author}

Juan José Álvarez is a Doctor of Law, in the area of Private International Law, by the UPV / EHU; He obtained the extraordinary Doctorate Award, along with the Extraordinary Degree Award and the Bachelor's Degree, with the Outstanding Qualification / Honor Roll. He received the Eusko-ikaskuntza-Laboral Kutxa Prize for Humanities, Culture, Arts and Social Sciences in 2015. He is a Professor of Private International Law at the UPV / EHU and a visiting professor at numerous universities and na- 
tional and European research centers. He also serves as Counselor-Lawyer of the law firm CUATRECASAS and is co-founder and Secretary of GLOBERNANCE (Institute for Democratic Governance). He was Secretary General of the Basque Council of the European Movement (EUROBASK / CVME) (May 2003-2012) and designated as expert by the EUROPEAN COMMISSION (Directorate General of Justice, Freedom and Security), dated December 17, 2007, for the Civil Justice areas, borders, personal data protection and security areas. His research focuses on Maritime Law, International Trade Law and Human Rights, European Law and areas related to internal conflicts. Among his latest research, we can mention «The Legal Lessons of the Prestige Case «. Towards a new Maritime Damage Law: current trends (ARANZADI THOMSON REUTERS, 2012), Human Rights in Business. Removal of Barriers to access to Justice in the European Union TAYLOR-FRANCIS, 2017), «Brexit and Gibraltar: the perspective of legal persons, incidence on the freedom of establishment and provision of services», the Brexit and Gibraltar. joint opportunities, Madrid, (DIPLOMATIC SCHOOL, 2017), «Marital Crises and Internal Law Conflicts», International Marital Crises and their effects. Spanish and European Union Law, TIRANT LO BLANCH, 2018). He is coordinator of the Spanish-French cross-border legal observatory and director of the University-Business Chair of CONFEBASK. 


\section{Derechos de autor}

Los derechos de autor (para la distribución, comunicación pública, reproducción e inclusión en bases de datos de indexación y repositorios institucionales) de esta publicación (Cuadernos Europeos de Deusto, CED) pertenecen a la editorial Universidad de Deusto. El acceso al contenido digital de cualquier número de Cuadernos Europeos de Deusto es gratuito inmediatamente después de su publicación. Los trabajos podrán leerse, descargarse, copiar y difundir en cualquier medio sin fines comerciales y según lo previsto por la ley; sin la previa autorización de la Editorial (Universidad de Deusto) o el autor. Así mismo, los trabajos editados en CED pueden ser publicados con posterioridad en otros medios o revistas, siempre que el autor indique con claridad y en la primera nota a pie de página que el trabajo se publicó por primera vez en CED, con indicación del número, año, páginas y DOI (si procede). Cualquier otro uso de su contenido en cualquier medio o formato, ahora conocido o desarrollado en el futuro, requiere el permiso previo por escrito del titular de los derechos de autor.

\section{Copyright}

Copyright (for distribution, public communication, reproduction and inclusion in indexation databases and institutional repositories) of this publication (Cuadernos Europeos de Deusto, CED) belongs to the publisher University of Deusto. Access to the digital content of any Issue of Cuadernos Europeos de Deusto is free upon its publication. The content can be read, downloaded, copied, and distributed freely in any medium only for non-commercial purposes and in accordance with any applicable copyright legislation, without prior permission from the copyright holder (University of Deusto) or the author. Thus, the content of CED can be subsequently published in other media or journals, as long as the author clearly indicates in the first footnote that the work was published in CED for the first time, indicating the Issue number, year, pages, and DOI (if applicable). Any other use of its content in any medium or format, now known or developed in the future, requires prior written permission of the copyright holder. 